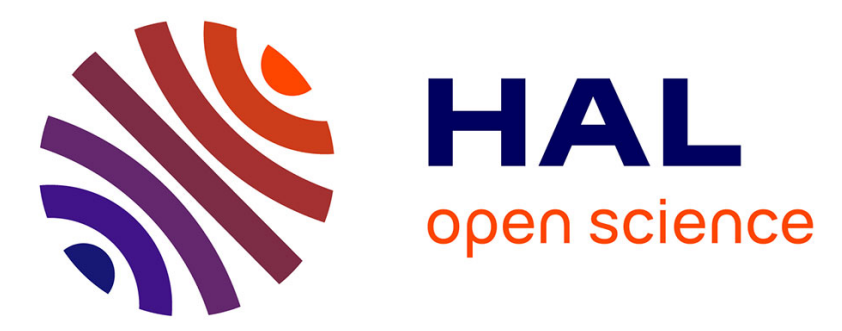

\title{
Loss assessment of a counter rotating open rotor using URANS/LES with phase-lagged assumption
}

\author{
Maxime Fiore, Majd Daroukh, Marc Montagnac
}

\section{To cite this version:}

Maxime Fiore, Majd Daroukh, Marc Montagnac. Loss assessment of a counter rotating open rotor using URANS/LES with phase-lagged assumption. Computers and Fluids, 2021, 228, pp.105025. 10.1016/j.compfluid.2021.105025 . hal-03325185

\section{HAL Id: hal-03325185 \\ https://hal.science/hal-03325185}

Submitted on 24 Aug 2021

HAL is a multi-disciplinary open access archive for the deposit and dissemination of scientific research documents, whether they are published or not. The documents may come from teaching and research institutions in France or abroad, or from public or private research centers.
L'archive ouverte pluridisciplinaire HAL, est destinée au dépôt et à la diffusion de documents scientifiques de niveau recherche, publiés ou non, émanant des établissements d'enseignement et de recherche français ou étrangers, des laboratoires publics ou privés. 


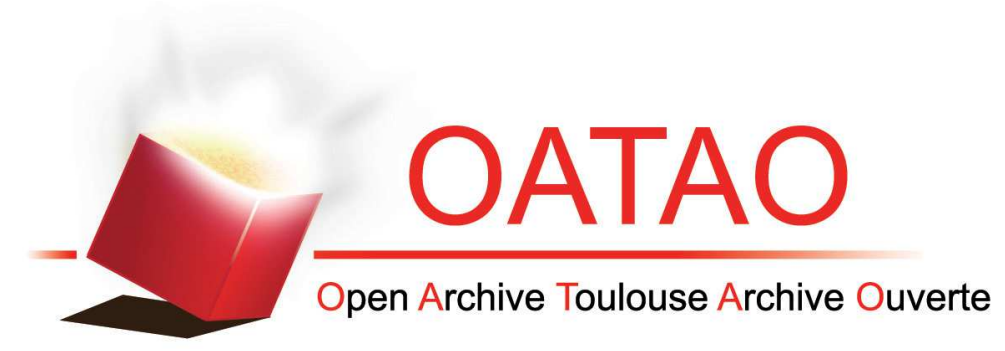

\section{Open Archive Toulouse Archive Ouverte (OATAO)}

OATAO is an open access repository that collects the work of some Toulouse researchers and makes it freely available over the web where possible.

This is an author's version published in: https://oatao.univ-toulouse.fr/28177

Official URL: https://doi.org/10.1016/j.compfluid.2021.105025

\section{To cite this version :}

Fiore, Maxime and Daroukh, Majd and Montagnac, Marc Loss assessment of a counter rotating open rotor using URANS/LES with phase-lagged assumption. (2021) Computers and Fluids, 228. 105025. ISSN 0045-7930

Any correspondence concerning this service should be sent to the repository administrator: tech-oatao@listes-diff.inp-toulouse.fr 


\title{
Loss assessment of a counter rotating open rotor using URANS/LES with phase-lagged assumption (draft)
}

\author{
M. Fiore ${ }^{\mathrm{c}, *}$, M. Daroukh ${ }^{\mathrm{b}}$, M. Montagnac ${ }^{\mathrm{a}}$ \\ a CERFACS, Computational Fluid Dynamics team, Toulouse, France \\ b ONERA, Aerodynamics, Aeroelasticity and Aeroacoustics Department, Châtillon, France \\ ${ }^{\mathrm{c}}$ ISAE-Supaero, Department of Aerodynamics, Energetics and Propulsion, Toulouse, France
}

Keywords:

Counter-Rotating Open Rotor (CROR)

Large-Eddy Simulation (LES)

URANS

Phase-lagged assumption

Proper Orthogonal Decomposition (POD)

Loss assessment

\begin{abstract}
A B S T R A C T
This paper presents the study of the losses generated in a Counter Rotating Open Rotor (CROR) configuration at three different operating conditions (approach, cutback and sideline). Unsteady Reynolds Averaged Navier-Stokes (URANS) and Large-Eddy Simulation (LES) approaches are used and compared to describe the flow field and the mechanisms of loss. Since no common circumferential periodicity occurs in the two blade rows of the configuration (11 blades for the front rotor and 9 for the rear rotor), a full $360^{\circ}$ simulation would be required. In order to reduce the related computational cost, a phase-lagged assumption approach is used. This method enables to perform unsteady simulations on multi-stage propulsive configurations including multiple frequency flows with a computational domain reduced to one single blade passage for each row. The phase-lagged approach requires a large data storage reduced in the study by a data compression method. The data compression method is based on a Proper Orthogonal Decomposition (POD) replacing the traditional Fourier Series Decomposition (FSD). The inherent limitation of the phaseshifted periodicity assumption remains with the POD data storage but this compression method alleviates some issues associated with the FSD, especially spectrum content issues. The analysis of the losses generated in the configuration is based on an entropy formulation. In particular, the losses are split between boundary layer contributions and the remaining domain where wakes and secondary flows occur. The study shows the influence of the leading edge vortex on the suction side boundary layer transition of the front and rear rotor blades at high rotational speed (cutback and sideline). The main source of losses is associated with the suction side boundary layer over the front and rear rotor blades with a main peak of loss production at around $75 \%$ of the blade chord.
\end{abstract}

\section{Introduction}

In order to decrease fuel consumption and greenhouse gases emissions of airplanes propulsion systems, new engines with significantly higher By-Pass Ratios (BPR) compared to current turbofan engines are being developed as Counter Rotating Open Rotor (CROR). These unducted architectures with specific blading designs and geometrical arrangements [45] considerably modify the flow topology and the mechanisms of loss generation compared to turbofan architectures [22]. Compared to contra-rotative ducted fan configurations [40] where a duct surrounds the rotors, CROR configurations are less efficient in producing thrust. Indeed, according to the actuator disk theory, the duct reduces the blade tip losses, enabling the ducted fans to increase the thrust $[24,43]$. The duct

\footnotetext{
* Corresponding author.

E-mail address: maxime.fiore@isae-supaero.fr (M. Fiore).
}

also reduces the rotors noise and protects the high-speed rotors from the external environment. For large propulsive configurations, the main advantage of CROR is the reduction of weight and drag related to a duct.

The development of such new aircraft engine designs has been widely performed numerically especially through the use of Unsteady Reynolds Averaged Navier-Stokes (URANS) simulations [4,6$8,28,39]$. Turbulent processes as tip vortex interaction, rotor wakes, transition processes on blades may limit the applicability of (U)RANS approaches where all turbulent structures are modelled. This observation pushes towards the use of lower levels of turbulence modelling like Large-Eddy Simulation (LES) approach [41] where the large energetic scales of turbulence are resolved and only the small scales are modelled. The use of LES in aircraft engine configurations is still challenging since the requirements for the meshing, numerics, convergence and data extraction are generally higher compared to (U)-RANS. In addition, the simulation domain can- 


\section{Nomenclature}

\section{Latin letters}

c speed of sound $\left[m \cdot s^{-1}\right]$

$\mathrm{C}_{x} \quad$ axial chord-length $[\mathrm{m}]$

$\mathrm{C}_{\mathrm{p}} \quad$ pressure coefficient [ - ]

$\mathrm{c}_{\mathrm{p}} \quad$ constant pressure heat capacity $\left[\mathrm{kg} \cdot \mathrm{m}^{2} \cdot \mathrm{s}^{-2} \cdot \mathrm{K}^{-1}\right]$

D rotor diameter $[\mathrm{m}]$

$\mathrm{H}$ shape factor [ - ]

$\mathrm{p} \quad$ pressure $\left[\mathrm{kg} \cdot \mathrm{m}^{-1} \cdot \mathrm{s}^{-1}\right]$

$\mathscr{P}_{\mathrm{k}} \quad$ turbulent kinetic energy production $\left[\mathrm{kg} \cdot \mathrm{m}^{2} \cdot \mathrm{s}^{-3}\right]$

$\mathrm{R} \quad$ gas constant $\left[\mathrm{kg} \cdot \mathrm{m}^{2} \cdot \mathrm{s}^{-2} \cdot \mathrm{K}^{-1} \cdot \mathrm{mol}^{-1}\right]$

$\mathrm{t}$ time [s]

$\mathrm{T}$ temperature $[K]$

$s \quad$ entropy $\left[\mathrm{kg} \cdot \mathrm{m}^{-1} \cdot \mathrm{s}^{-2}\right]$

$\mathrm{u} \quad$ velocity $\left[m \cdot s^{-1}\right]$

$(x, y, z)$ cartesian coordinates $[m]$

\section{Greek letters}

$\delta \quad$ boundary layer thickness $[\mathrm{m}]$

$\lambda$ thermal conductivity $\left[\mathrm{kg} \cdot \mathrm{m}^{-1} \cdot \mathrm{s}^{-1}\right]$

$\kappa \quad$ artificial viscosity coefficient [ - ]

$\mu \quad$ dynamic viscosity $\left[\mathrm{kg} \cdot \mathrm{m}^{-1} \cdot \mathrm{s}^{-1}\right]$

$v \quad$ kinematic viscosity $\left[\mathrm{m}^{2} \cdot \mathrm{s}^{-1}\right]$

$\omega \quad$ rotational speed $\left[\mathrm{rad} . \mathrm{s}^{-1}\right.$ ]

$\rho \quad$ density $\left[\mathrm{kg} \cdot \mathrm{m}^{-3}\right.$ ]

$\tau \quad$ viscous shear stress $\left[\mathrm{kg} . \mathrm{m}^{-1} \cdot \mathrm{s}^{-2}\right]$

$\theta \quad$ momentum thickness $[\mathrm{m}]$

\section{Abbreviations}

$\operatorname{Re}_{C_{x}} \quad$ Reynolds number $\mathrm{u} C_{x} / v$

$\mathrm{AP}, \mathrm{CB}, \mathrm{SL}$ approach, cutback, sideline

CROR Counter Rotating Open Rotor

FSD Fourier Series Decomposition

LES Large-Eddy Simulation

POD Proper Orthogonal Decomposition

URANS Unsteady Reynolds Averaged Navier-Stokes

LE/TE Leading Edge/Trailing Edge

SS/PS Suction Side/Pressure Side

LES Large-Eddy Simulation

Ma Mach number

NSCBC Navier-Stokes Characteristic Bound. Cond.

R1/R2 Rotor 1/rotor 2

(U)RANS (Unsteady) Reynolds Averaged Navier-Stokes

SGS Sub-Grid Scale model

WALE Wall-Adapting Local Eddy-viscosity

\section{Subscripts and superscripts}

$\infty \quad$ upstream condition

max maximum

P.C. periodic conditions

P.L. phase-lagged simulation

RMS root mean square

tot total quantity

SGS subgrid scale contribution

.$^{+} \quad$ non-dimensional wall-units

. $\quad$ fluctuating quantity

edge boundary layer edge quantity

in/out inlet/outlet conditions

tot total

turb turbulent

eff effective

ref reference state

.$^{+} \quad$ non-dimensional wall distance

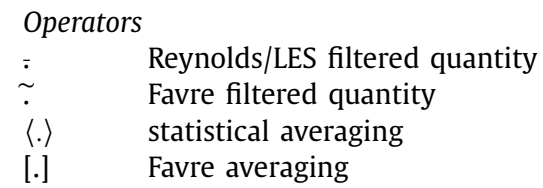

not be reduced using periodic boundary conditions due to a coprime number of blades for the two counter rotating rows. In order to alleviate the cost of a full $360^{\circ}$ simulation, some paths have been investigated to reduce the computational cost of LES with acceptable physical restrictions. For this purpose, the use of phaselagged boundary conditions allows the $360^{\circ}$ simulation domain to be reduced to a single passage per row, as proposed by Erdos and Alzner [14]. The main difficulty with this approach lies in the necessary storage of the flow variables at each time step over a full passage of the opposite blade at the phase-lagged interfaces. In multi-row simulations, it corresponds to the storage of the flow variables at the interface between static and rotating domains and on lateral azimuthal conditions. For the meshes and time steps considered in practical turbomachinery simulations, direct storage represents a significant cost. The most popular method to reduce the data storage cost is to perform a Fourier Series Decomposition (FSD) of the temporal signal at the phase-lagged interfaces, as proposed by He [20,21]. The FSD is truncated to a limited number of harmonics, and the coefficients are updated at each time step with the shape correction method. This method assumes the flow perfectly periodic in time, which is a fair assumption in URANS for operating points dominated by periodic rotor-stator interactions (wakes and potential effects). For LES, the periodic assumption is no longer true. In particular, LES includes multiple unknown frequencies, for example non-deterministic small scales structures in a turbulent wake, for which the characteristic time that needs to be used is unknown. Keeping the limitation of the phase-lagged assumption, a data storage based on a Proper Orthogonal Decomposition (POD) [2] has been developed and implemented in the elsA software [3] by Mouret et al. [32] used to perform the present URANS/LES. This compression method especially improves some issues associated with the FSD and the corresponding spectrum content.

The purpose of this paper is to describe the mechanisms of losses in the full CROR configuration for different operating points: approach (AP), cutback (CB) and sideline (SL) based on URANS and LES with phase-lagged conditions and POD data storage. The capability of URANS/LES with phase-lagged assumption and POD data storage to properly capture the physical phenomena in the configuration is assessed by comparing against experimental data available in the wake of the front rotor alone.

The paper is organized as follows: Section 2 introduces the configuration and numerical setup; the method used to measure the losses generated in the configuration is described in Section 3; the comparison of the numerical simulations against experimental data for the front rotor is presented in Section 4; the description of the flow field including pressure distribution around the blade and near-wall flow is introduced in Section 5; the description of the loss mechanisms is introduced in Section 6.

\section{Configuration and numerical methods}

The open-rotor configuration used for the study is the Airbus Clean Sky generic Open Rotor configuration AI-PX7 11x9 at scale $1 / 7$. Fig. 1 shows the geometry of this rear fuselage pylon-mounted pusher configuration. The front rotor is composed of 11 blades and 9 blades for the rear rotor. The number of blades is a trade-off between aerodynamic efficiency/noise reduction and structural con- 
Table 1

Main characteristics of the CROR AI-PX7 and experimental conditions for he different operating points: approach (AP), cutback (CB) and sideline (SL).

\begin{tabular}{llll}
\hline cascade details & \multicolumn{3}{c}{ nominal conditions } \\
\hline Front rotor blades & 11 & Inc. angle $\left[{ }^{0}\right]$ & 0 \\
Rear rotor blades & 9 & $p_{\text {tot }, \infty}[\mathrm{Pa}]$ & 101,179 \\
Hub-to-tip ratio & 0.35 & $T_{\text {tot, } \infty}[\mathrm{K}]$ & 311.5 \\
Rear rotor cropping [\%] & 10 & ${\text { Rot. speed } \omega\left[\text { rad.s }^{-1}\right]}_{12}$ & $512.4(\mathrm{AP}) 663.2(\mathrm{CB}) 738.2(\mathrm{SL})$ \\
$\mathrm{L}_{\mathrm{R} 1-\mathrm{R} 2} / \mathrm{D}$ & 0.22 & $\operatorname{Re}_{\mathrm{C}_{\mathrm{x}}}$ & $1.1 \times 10^{6}$ \\
Nacelle length/D & 6 & $\mathrm{Ma}_{\infty}$ & 0.2 \\
\hline
\end{tabular}
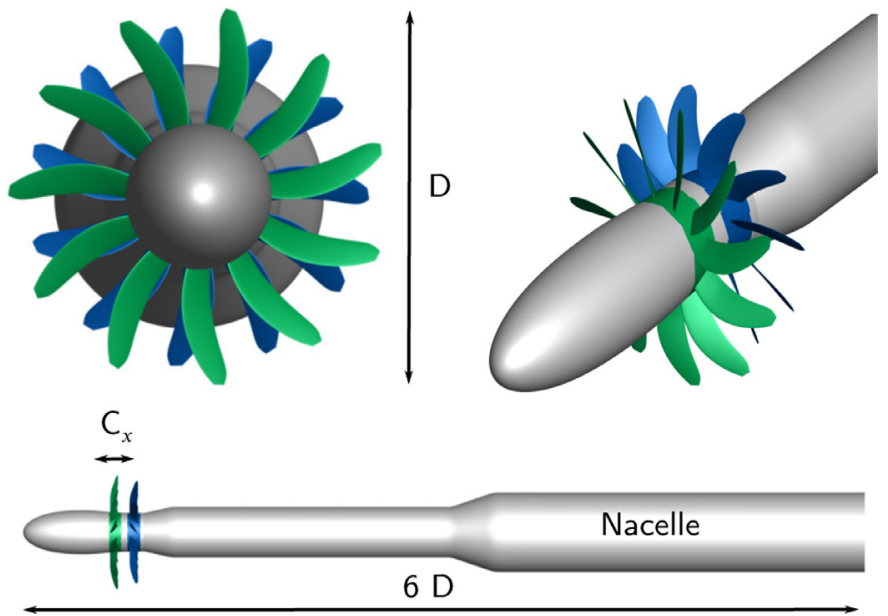

Fig. 1. Geometrical setup with front and rear rotors highlighted.

straints. For aerodynamic and acoustic reasons, a high number of blades is preferred since a higher efficiency can be reached and the noise is shifted to higher frequencies, reducing thus the perceived noise. From a structural point of view, fewer blades with a large chord are preferred in order to keep stresses low and to lower the flutter risks. The number of blades for the rear rotor is lower compared to the front rotor to account for the front rotor wake impingement increasing mechanical constraints. The axial distance between the front and rear rotor is set to $L_{R 1-R 2} / D=0.23$ where $\mathrm{D}=0.61 \mathrm{~m}$ is the rotor diameter as a trade-off between a larger distance to promote the front rotor wake dissipation before to impact the rear rotor and a limited length to reduce weight and drag of the configuration. The rear rotor is cropped in order to avoid the front rotor tip vortices to impact the rear rotor (10\% cropping compared to the front rotor). The front and rear rotor are designed with positive sweeping on the upper part of the blade to reduce the normal Mach number and related shock losses and noise. The main geometrical features are gathered in Tab. 1 left column with more details about the CROR AI-PX7 design provided in Negulescu et al. [33]. This configuration has been implemented and tested in the Airbus low-speed wind-tunnel (LWST) in Bremen, Germany by the DLR. The facility is an open-type wind tunnel with a closed test section of $2.1 \times 2.1 \times 4.45 \mathrm{~m}$. The instrumentation allows measuring open-rotor overall performance and wake analysis through Particle Image Velocimetry (PIV) measurements downstream of the blade. PIV measurements are performed in a phase-locked fashion with respect to the passage of a single blade. More details about the experimental facility, PIV calibration and data processing are provided in Novara et al. [36].

Two different geometries are investigated for the study. A first geometry composed on the front rotor only and a second geometry with the front and rear rotors. For the geometry with the front rotor only, two different simulation domains are considered and one simulation domain for the full CROR configuration. Fig. 2 shows the simulation domains for the two different geometries investigated. For all the simulations, the domain is composed of two sub-domains: one sub-domain extending from the inlet set upstream of the configuration to the mid-position between front rotor (R1) trailing edge and rear rotor (R2) leading edge; a second sub-domain extending from this same position to the outlet set downstream of the rear rotor. For the geometry with the front rotor only composed of 11 blades, 1/11 of the full azimuthal domain is considered for the two sub-domains with a full-matching interface between the two sub-domains and periodic conditions are applied on the lateral surfaces. URANS and LES are performed on this configuration denoted R1PC where R1 stands for the front rotor only considered and PC for periodic conditions. On this same geometry, a LES with phase-lagged assumption and POD data compression is performed over a different simulation domain: the front sub-domain is identical to the one used for the reference simulations $\left(\right.$ URANS $_{\text {R1PC }}$ and LES $_{\text {R1PC }}$ ) but a larger rear sub-domain (1/9 of the whole azimuthal domain) rotating in opposite direction with respect to the front sub-domain is used. This computational domain mimics a hypothetical rear counter rotating rotor row with nine blades of a CROR configuration. This configuration is denoted R1PL where PL stands for phase-lagged. The comparison of the URANS $_{\mathrm{R} 1 \mathrm{PC}}$ with $\mathrm{LES}_{\mathrm{R} 1 \mathrm{PC}}$ makes possible to highlight the influence of the turbulence modeling and $\mathrm{LES}_{\mathrm{R} 1 \mathrm{PC}}$ with $\mathrm{LES}_{\mathrm{R} 1 \mathrm{PL}}$ the influence of the phase-lagged condition with POD data storage. Finally, URANS and LES with phase-lagged assumption are performed with the same computational domain compared to R1PL except that the rear rotor stage is added to simulate the full CROR configuration. This configuration is denoted R12PL where R12 stands for the rotor 1 and 2 considered. For all the configurations, the simulation domain extends $4 \mathrm{D}$ upstream of the front of the configuration in the streamwise direction. The outlet is set at the rear of the nacelle which is $5 \mathrm{D}$ long. The radius of the simulation domain is $3.5 \mathrm{D}$.

The boundary conditions imposed at the free surfaces are extrapolation conditions of the reference state (see Table 1 right column) and are also used as an initial solution for the simulations. Adiabatic and non-slipping wall conditions are applied on the blades and nacelle walls. At the full non-matching interface and on the lateral surfaces, phase-lagged conditions are applied for the R1PL and R12PL configurations while full-matching interface and periodic conditions are applied on the lateral surfaces for the R1PC configuration.

The same meshing strategy and refinement are used for the different numerical approaches and geometries investigated. The details are provided for the full CROR configuration in LES with phase-lagged assumption ( $\left.\mathrm{LES}_{\mathrm{R} 12 \mathrm{PL}}\right)$. The meshing strategy is based on an $0-6 \mathrm{H}$ block for the two rotor rows. Fig. 3 shows the mesh refinement around the front rotor blade at mid span. The first offwall point is set to $\Delta y / C_{x}=4 \times 10^{-5}$. According to the literature $[18,37,38]$, the near-wall region should be resolved with $50 \leq$ $\Delta x^{+} \leq 80 ; \Delta y^{+} \leq 1 ; 15 \leq \Delta z^{+} \leq 25$. These criteria are challenging to fulfil for the present configuration with a high Reynolds number and large dimensions. In wall-resolved LES, the long and flow aligned structures close to the wall [44] known as streaks are 

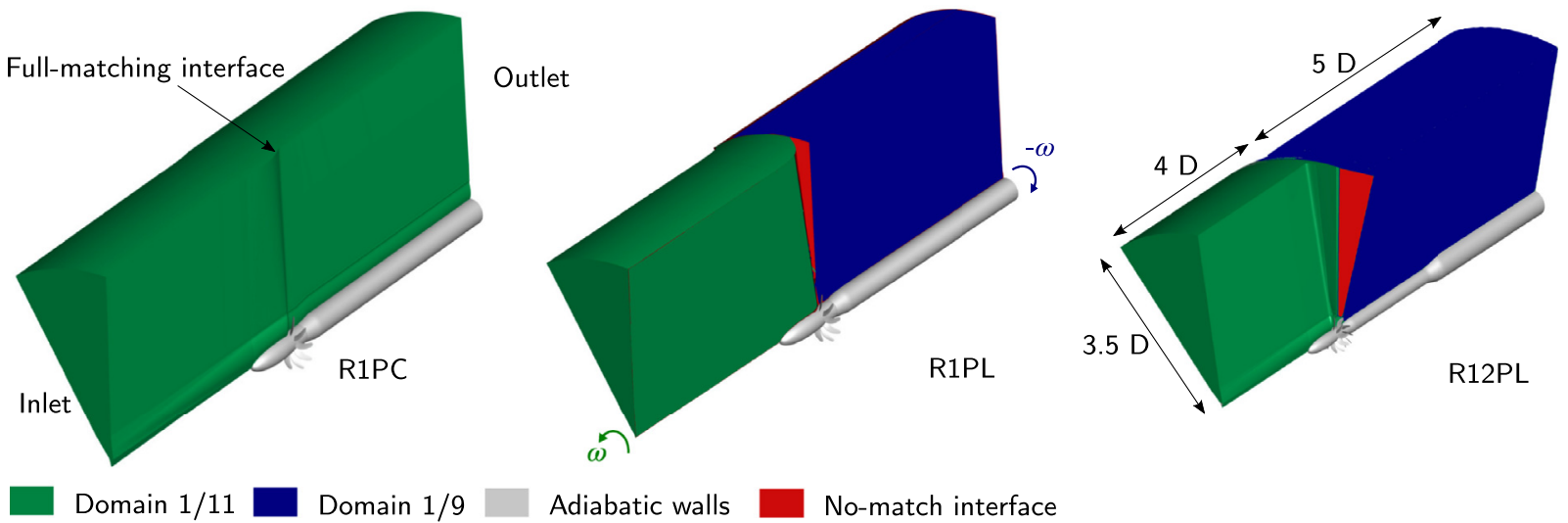

Domain $1 / 1$

Adiabatic walls

No-match interface

Fig. 2. Simulation domains. Matching interface for the R1PC (domain 1/11-1/11) and no-match interface for the R1PL and R12PL (domain 1/11-1/9).

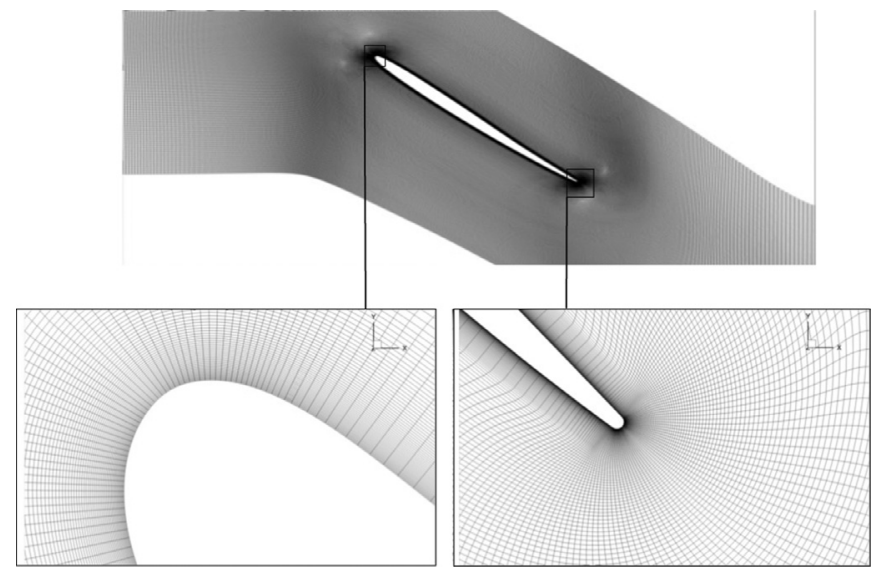

Fig. 3. Meshing around the front rotor blade at mid span.

important structures to be captured. These structures are shown to have lower variations in the $\mathrm{x}$ direction compared to the $\mathrm{y}$ and $\mathrm{z}$ directions. Therefore, the mesh has been mainly coarsened in the $\mathrm{x}$ direction. In the spanwise direction, around 700 layers have been set over a spanwise length of around $15 \mathrm{~cm}$ with a grid refinement close to the nacelle wall (expansion ratio of 1.05). This distribution provides a mean spanwise coordinate of $\Delta z^{+} \simeq 60$. In the streamwise direction, around 400 points have been set for a mid span chord length of $10 \mathrm{~cm}$ corresponding to a mean streamwise coordinate of $\Delta x^{+} \simeq 100$. Fig. 4 shows the mid span grid dimensions at the front and rear rotor blade walls based on $\mathrm{LES}_{\mathrm{R} 12 \mathrm{PL}}$ for the SL operating point confirming the targeted value for the first off-wall points. The mesh cells are built to have orthogonality higher than $30^{\circ}$ and in near-wall region higher than $80^{\circ}$. The stretching ratio between the size of neighbouring cells in the blade wall-normal direction was set to 1.03 to guaranty around 30 grid points in the viscous layer until $\Delta y^{+}=50$. The mesh is refined in the wake to properly propagate the structures developing at the trailing edge of the front and rear rotor blades. The mesh is composed of around $250 \times 10^{6}$ cells for the URANS $S_{\mathrm{R} 1 \mathrm{PC}}$ and LES $\mathrm{R}_{\mathrm{PC}}, 270 \times 10^{6}$ cells for

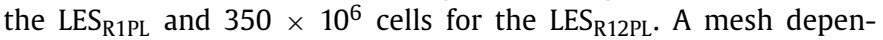
dency is proposed in App. Appendix A.

The simulations are performed using the ONERA elsA software [3] solving the compressible Navier-Stokes equations over multi-block structured grids and used in previous studies for openrotor characterization and optimization $[10,11,15]$. For the URANS simulation, an upwind Roe scheme with third-order limiter [35] is used for the convective terms. The Wilcox $\mathrm{k}-\omega$ two-equations model with Zheng's limiter [47] is used according to the practice

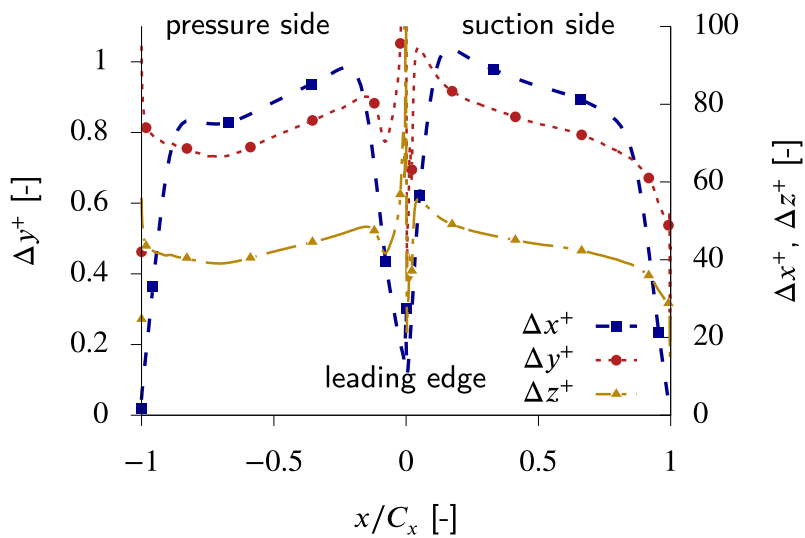

(a)

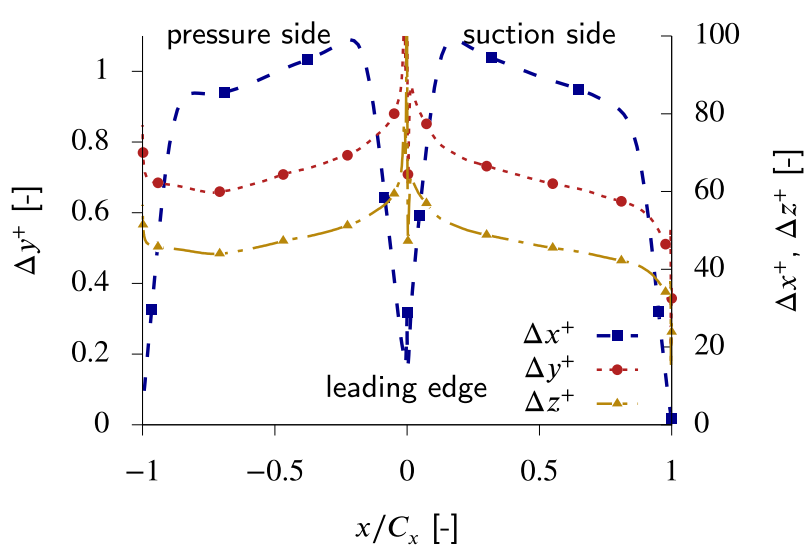

(b)

Fig. 4. Grid dimensions at the front (a) and rear rotor walls (b) at mid span for SL based on the $\mathrm{LES}_{\mathrm{R} 12 \mathrm{PL}}$ approach.

provided by Gourdain et al. [16,17] in a turbomachinery context. For the LES, a second order centred scheme with a low Jameson artificial viscosity [23] $\left(\kappa_{\mathrm{jam} .}^{4}=0.002\right)$ is used for the convective discretization. The subgrid scale model is the Wall-Adapting Local Eddy-viscosity (WALE) [34]. For the URANS and LES approaches, the time integration is performed using a Dual Time Stepping (DTS) with a Crank-Nicholson scheme (second order accurate) in combination with an implicit pseudo-time stepping for the inner loops [29]. The time step is set to $\Delta t^{+}=\Delta t \mathrm{u}_{\infty} / C_{x}=1 \times 10^{-3}$ corresponding to 11,880 iterations per full rotation. The number 
of POD modes used to perform the data compression is set to 30 based on previous studies [32] and to properly conserve at the phase-lagged interfaces the vortex shedding spectral content generated in the wake of the front and rear rotor. The storage of azimuthal and non-matching R1-R2 surfaces at each time step for one full rotation in LES represents a storage requirement of 68.2 Giga bytes in POD compared to 226.6 Giga bytes for a direct storage. The POD technique used with the update of the coefficient along time represents an overcost of around $24 \%$ compared to the classical spatial and temporal integration in the solver.

\section{Measure of loss based on entropy}

The increase of entropy in the simulation domain can be used to describe the losses generated in the configuration as popularized by Denton in a gas turbine context [12]. Mainly two approaches can be used to measure the entropy denoted $s$ in the simulation domain. A first approach based on two independent thermodynamic quantities of the flow, for example pressure $p$ and temperature $T$ leading to:

$s-s_{\text {ref }}=c_{\mathrm{p}} \ln \left(T / T_{\text {ref }}\right)-R \ln \left(p / p_{\text {ref }}\right)$

where $c_{p}$ is the constant pressure heat capacity, $R$ the gas constant, $s_{\text {ref }}, p_{\text {ref }}$ and $T_{\text {ref }}$ reference entropy, pressure and temperature. Alternatively, entropy can be calculated locally in each cell grid and is composed of two contributions: a viscous and a thermal contribution that can be written in (U)RANS formalism:

$s_{\nabla \mathrm{u}}(x)=\iiint_{\mathcal{V}, 0 \rightarrow x} \overline{\tau_{i j, \mathrm{eff}}} \frac{1}{\bar{T}} \frac{\partial \overline{u_{i}}}{\partial x_{j}} \mathrm{~d} \mathcal{V}$

$s_{\nabla T}(x)=\iiint_{\mathcal{V}, 0 \rightarrow x}\left(\lambda+\lambda_{\text {turb }}\right) \frac{1}{\bar{T}^{2}}\left(\frac{\partial \bar{T}}{\partial x_{j}}\right)^{2} \mathrm{~d} \mathcal{V}$

where $\tau_{i j, \text { eff }}=\left(\mu+\mu_{\text {turb }}\right)\left(\partial \overline{u_{i}} / \partial x_{j}+\partial \overline{u_{j}} / \partial x_{i}\right)$ is the effective viscous stress tensor and - the Reynolds averaged quantities as a direct output of the simulation. In a turbulent flow, it corresponds to a mean contribution sometimes called laminar contribution and a turbulent one [26]. The former contribution is only due to the mean flow distortion. The latter contribution is induced by turbulence: the mean flow energy at large scale is dissipated at small scales in internal energy (heat) and induces the non-locality between mean energy flow lost and equivalent heat generated at small scales. The (U)RANS approach provides a direct splitting between the mean contribution through the natural viscosity of the fluid $(\mu)$ and the turbulent contribution with the equivalent turbulent viscosity $\left(\mu_{\text {turb }}\right)$ [31]. The total contribution is obtained by summing the two contributions as provided in eq.(2):

$\left[\begin{array}{c}s_{\nabla \mathrm{u}, \text { mean }} \\ s_{\nabla \mathrm{u}, \text { turb }}\end{array}\right]=\iiint_{\mathcal{V}}\left[\begin{array}{c}\mu \\ \mu_{\text {turb }}\end{array}\right]\left(\frac{\partial \overline{u_{i}}}{\partial x_{j}}+\frac{\partial \overline{u_{j}}}{\partial x_{i}}\right) \frac{1}{\bar{T}} \frac{\partial \overline{u_{i}}}{\partial x_{j}} \mathrm{~d} \mathcal{V}$.

In LES, the splitting can be obtained by taking advantage of the unsteady nature of the method. The total viscous irreversibilities produced $s_{\nabla \mathrm{u}}$ can be written as $[25-27,30,46]$ :

$s_{\nabla \mathrm{u}}=s_{\nabla \mathrm{u}, \text { mean }}+P_{\mathrm{k}}$

where $s_{\nabla \mathrm{u} \text {,mean }}$ is the mean viscous dissipation and $P_{\mathrm{k}}$ is the Turbulent Kinetic Energy (TKE) production term. These different contributions can be expressed as:

$s_{\nabla \mathrm{u}, \text { mean }}=\iiint_{\mathcal{V}}\left(\mu+\mu_{\mathrm{SGS}}\right)\left(\frac{\partial\left[u_{i}\right]}{\partial x_{j}}+\frac{\partial\left[u_{j}\right]}{\partial x_{i}}\right) \frac{1}{\bar{T}} \frac{\partial\left[u_{i}\right]}{\partial x_{j}} d \mathcal{V}$

$\mathscr{P}_{\mathrm{k}}=\iiint_{\mathcal{V}}-\left\langle\bar{\rho} u_{i}^{\prime} u_{j}^{\prime}\right\rangle \frac{\partial\left[u_{i}\right]}{\partial x_{j}} d \mathcal{V}$

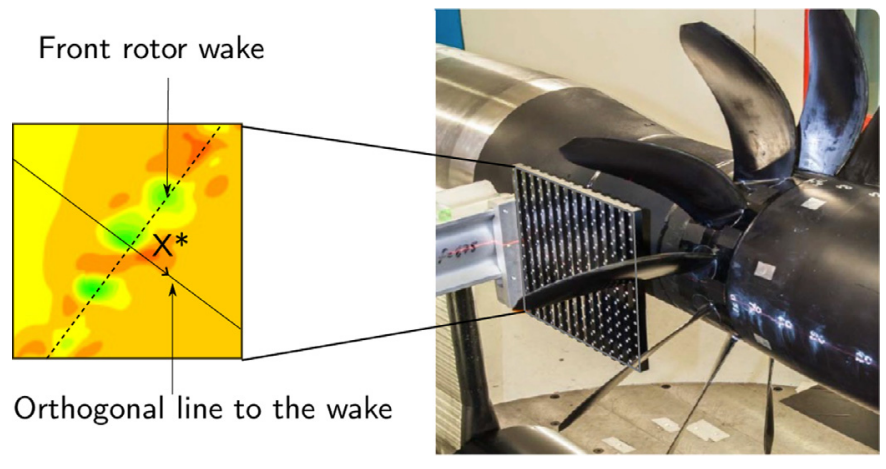

Fig. 5. PIV measurements location downstream of $R 1$ and orthogonal line to the wake.

where $\mu_{\text {SGS }}$ is the equivalent sub-grid scale viscosity, the overbar : denotes the filtered quantity as an output of the LES. The tilde ? denotes a quantity calculated from the filtered variables $\bar{\rho}, \overline{\rho u_{i}}$ and $\bar{p}$. Thus the calculated velocity is $\tilde{u}_{i}=\overline{\rho u_{i}} / \bar{\rho}$ using Favre filtering. The statistical averaging is denoted by $\langle$.$\rangle and Favre averaging by$ [.] yielding to $\left[\mathrm{u}_{i}\right]=\left\langle\rho u_{i}\right\rangle /\langle\rho\rangle$ for instance. The fluctuating velocity is defined by $u_{i}^{\prime}=\tilde{u}_{i}-\left[u_{i}\right]$.

\section{Comparison against experimental data}

The velocity field downstream of the R1 is measured experimentally with a PIV system [1]. Fig. 5 shows the PIV measurements performed along a square plane of $0.1 \mathrm{~m} \times 0.1 \mathrm{~m}$ set downstream of $\mathrm{R} 1$ at a constant height (69\% of blade span) in an (x,y) plane where $\mathrm{z}$ is the spanwise direction. The velocity profiles are extracted over a line orthogonal to the wake. Fig. 6 shows the corresponding comparison of the mean axial velocity and fluctuations for the numerical simulations and the experiments along this line for the $\mathrm{CB}$ operating point.

The URANS $_{\mathrm{R} 1 \mathrm{PC}}$, $\mathrm{LES}_{\mathrm{R} 1 \mathrm{PC}}$ and $\mathrm{LES}_{\mathrm{R} 1 \mathrm{PL}}$ show a good agreement with the experiments for the mean velocity magnitude out of the wake. In the wake region characterized by the velocity deficit, the

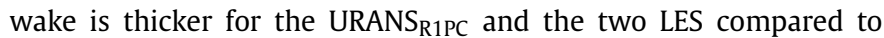
the experiments. Also, the velocity deficit is lower compared to the experiments with a discrepancy of $4 \%$. A similar trend is observed on the axial velocity fluctuations with a larger wake and lower velocity fluctuations in the numerical simulations compared to the experiments. The $\mathrm{LES}_{\mathrm{R} 1 \mathrm{PL}}$ shows a marginal lower turbulent activity compared to the $\mathrm{LES}_{\mathrm{R} 1 \mathrm{PC}}$. The POD data storage is able to reduce the data filtering compared to Fourier data storage but a residual part of the wake structure is inherently lost due to the phaselagged assumption as previously noticed by Mouret et al. [32]. The $\mathrm{CB}$ operating point is characterized by a leading edge vortex promoting the separation of the boundary layer on the blade suction side (SS) from mid to tip span. The boundary layer thickness over the blade and as a consequence the wake deficit width are very sensitive to the leading edge vortex and may explain the differences observed for the wake profile between the numerical simulations and the experiments.

Despite this potential discrepancy in the separation process, the numerical simulation matches well the experiments and promotes its use for the description of losses in the configuration. In particular, the LES more accurately captures the wake deficit region compared to the URANS approach. Furthermore, the phase-lagged assumption with POD data storage shows a good behavior compared to the full-matching approach in LES and gives more confidence in its use for the full CROR configuration where the rear rotor is considered. 


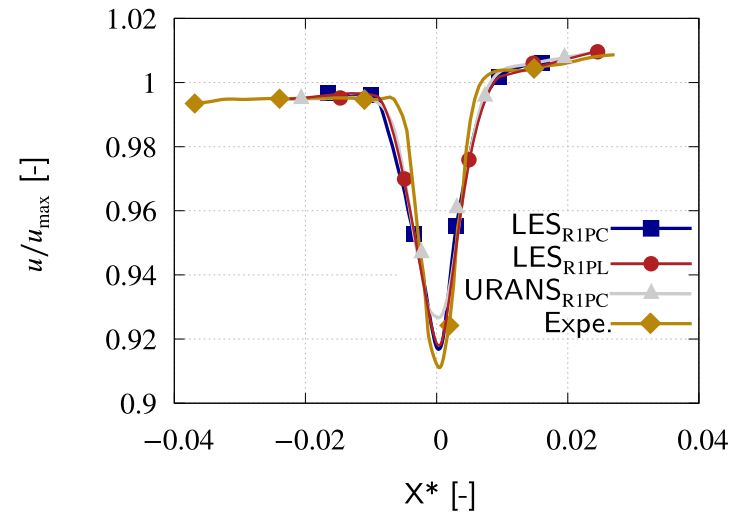

(a)

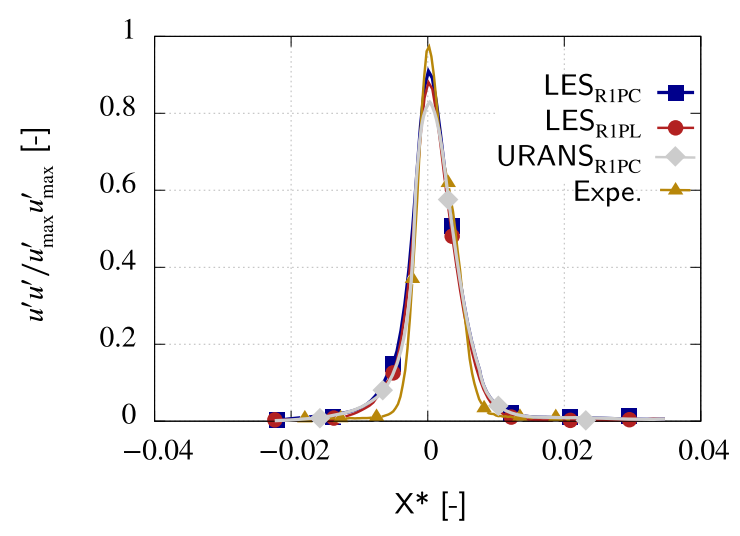

(b)

Fig. 6. Normalized axial velocity $u$ (a) and squared axial velocity fluctuation $u^{\prime} u^{\prime}$ (b) downstream of R1 at CB from the simulations and experiments.

\section{Analysis of the flow field}

Fig. 7 shows the axial Mach $\left(\mathrm{Ma}_{x}\right)$ at $80 \%$ of the front rotor radius for the three different operating points (AP, CB, SL) in URANS and LES based on the R12PL configuration (denoted URANS and LES in the next Sections). The incoming flow at $\mathrm{Ma}=0.2$ is accelerated by the two counter rotating rows to $\mathrm{Ma}_{x}=0.35$ for the $\mathrm{AP}, \mathrm{Ma}_{x}=0.45$ for the $\mathrm{CB}$ and $\mathrm{Ma}_{x}=0.55$ for the SL operating point downstream of the rear rotor. The low axial gap between the front and rear rotor promotes the interaction of the front rotor wake with the rear rotor blades.

\subsection{R1 flow topology}

Fig. 8 shows the time-averaged pressure coefficient $C_{p}=-p / p_{\text {inf }}$ around the R1 at 10, 50 and $90 \%$ of the blade height for the different operating points obtained with URANS. For the different blade heights, the curvature at the leading edge of the R1 SS induces a strong velocity increase and consequently a decrease of the pressure. Conversely, on the Pressure Side (PS), the velocity decreases and produces an overpressure. The pressure then increases on the SS and decreases on the PS until $x / C_{x}=0.5$ where the values of pressure coefficient become nearly constant until the trailing edge. The pressure loading of the front rotor of the CROR studied mainly occurs close to the leading edge compared to more conventional airfoils where the pressure coefficient distribution leads to a more balanced loading over the full chord. For the full scale geometry and for the design point at cruise, the CROR operates with shocks structures over a large part of the span. The large increase of the velocity at the front of the blade on the SS induced by the blad-
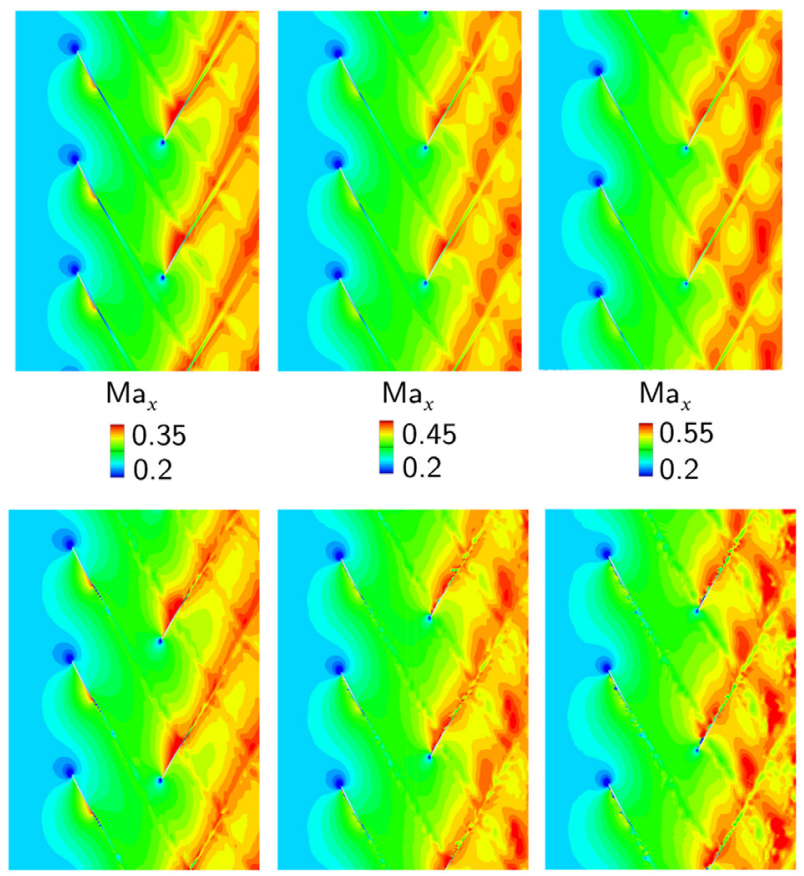

Fig. 7. Instantaneous blade-to-blade view of the flow at $80 \%$ span for the three operating points: AP (left), CB (center), SL (right) for the URANS ${ }_{\mathrm{R} 12 \mathrm{PL}}$ (top) and $\mathrm{LES}_{\mathrm{R} 12 \mathrm{PL}}$ (bottom).

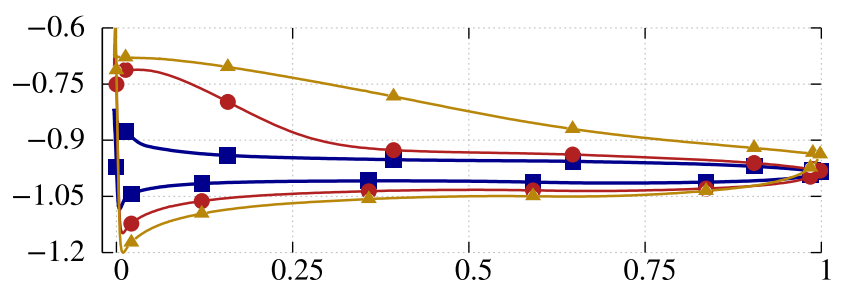

(a)

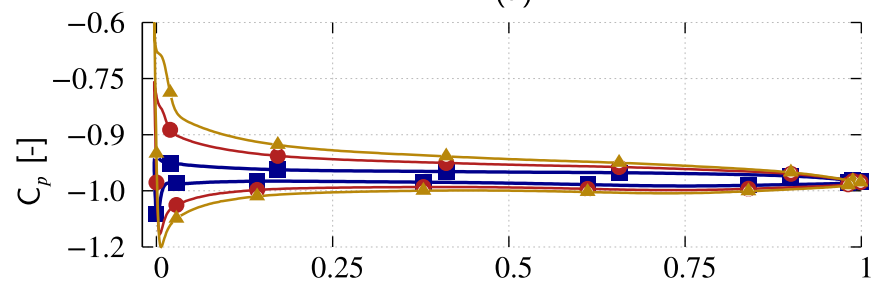

(b)

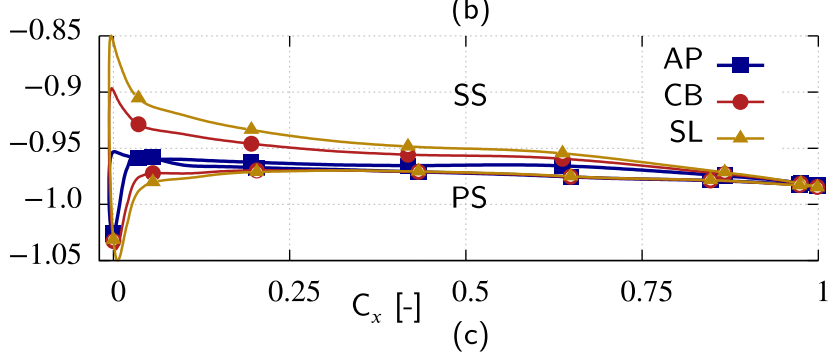

Fig. 8. Pressure coefficient distribution around the R1 blade at 90\% (a) 50\% (b) and $10 \%$ (c) of the blade height for the different operating points based on URANS.

ing design sets the shock structures close to the leading edge. The losses associated with the reacceleration of the flow downstream of the shock are reduced compared to conventional airfoils and are beneficial for the efficiency of the CROR [28]. Based on the boundary layer edge detection method available in elsA [5,9], the boundary layer thickness and shape factor $\mathrm{H}=\delta^{*} / \theta$ where $\delta^{*}$ and $\theta$ are the displacement and momentum thickness around the front and 


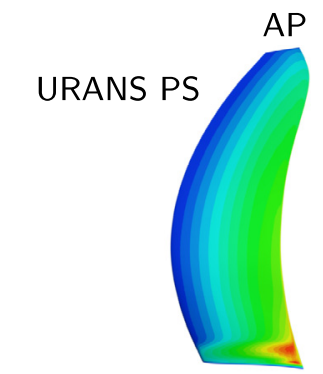

AP
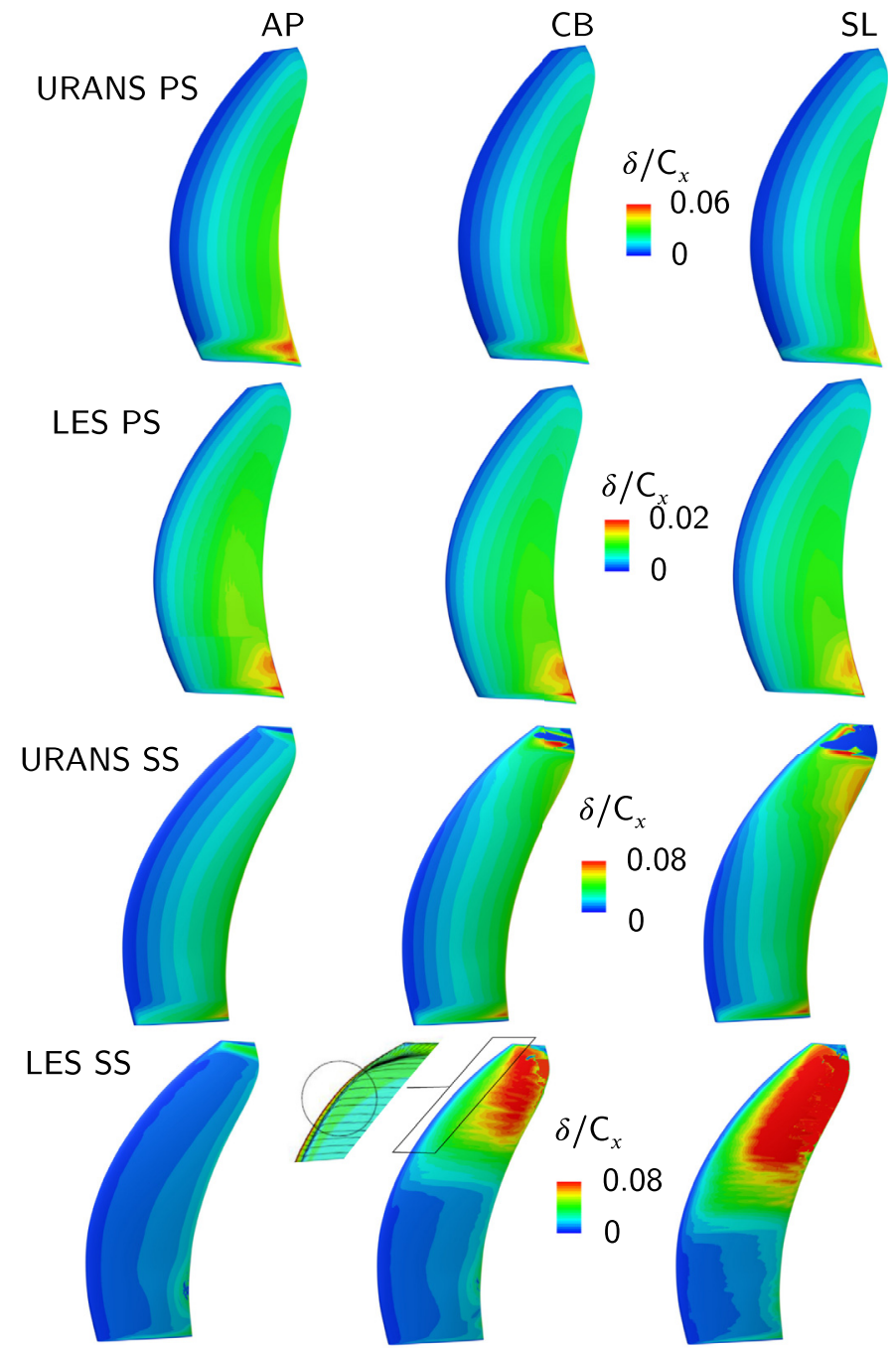

$\delta / C_{x}$
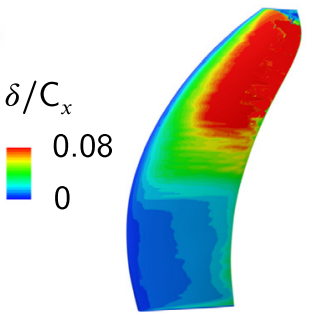

Fig. 9. Boundary layer thickness $\delta$ around the R1 PS and SS for the URANS and LES, streamlines characterizing the leading edge vortex (bottom center).

rear rotors can be obtained for the URANS and LES. Figs. 9 and 10 (lines 1 and 3 ) show the boundary layer thickness and shape factor around the PS and SS of the front rotor for the different operating points based on the URANS computations. Based on the Blasius profile, i.e., solution of the steady two-dimensional Prandtl equation in laminar regime, the value for $\mathrm{H}$ corresponding to laminar flows is 2.59 while 1.3 to 1.4 is typical of turbulent flows ${ }^{1}$ [42]. The boundary layer is characterized by high values of $\mathrm{H}$ at the leading edge where the boundary layer starts to develop and reach values of $\mathrm{H}=1.3$ characterizing a turbulent boundary layer over the PS and SS of the front rotor for the URANS approach. Close to the tip, the boundary layer thickness is predicted to decrease with the chord. This behavior is rather associated to the difficulty for the boundary layer edge detection method to predict the boundary layer thickness over surfaces where secondary vortices travel, the tip vortex for the present case.

Figs. 9 and 10 (lines 2 and 4) show the boundary layer thickness and shape factor for the front rotor PS and SS based on the LES. The PS boundary layer is fully attached with values of $\mathrm{H}$ around 2.5

\footnotetext{
1 This criterion based on the flow over a flat plate without pressure gradient is considered a good approximation in the configuration since the curvature of the blade is low. Moreover, the flow is relatively two-dimensional except in secondary vortices regions at the junction between nacelle and blade and the pressure gradients are moderate
}

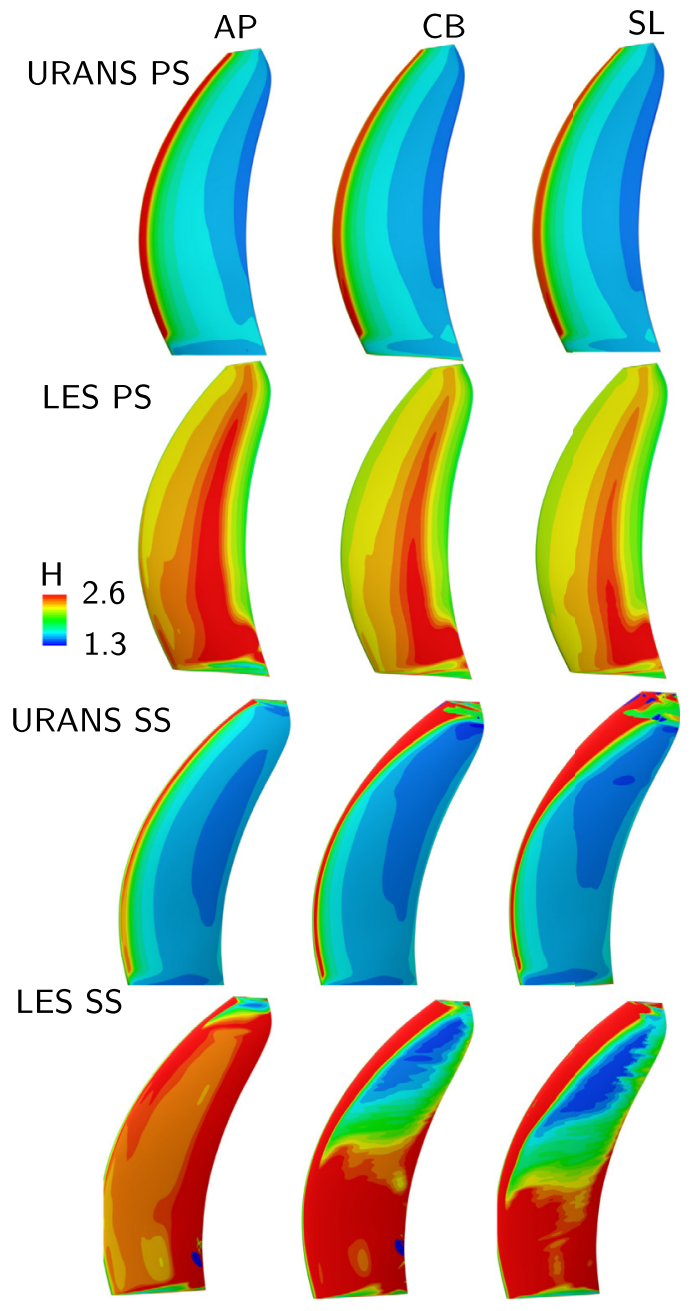

Fig. 10. Boundary layer shape factor $H$ around the R1 PS and SS for the URANS and LES.

characterizing a laminar boundary layer for the three different operating points. Also, the boundary layer is thinner compared to the URANS approach due to the stronger growth rate of the turbulent boundary layer compared to the laminar one. On the SS, for the AP operating point, the boundary layer is fully laminar. For the $\mathrm{CB}$ and SL operating points, the boundary is laminar from the hub to mid span and becomes turbulent from mid to tip span with an increase of the turbulent region size with the rotating speed. This boundary layer transition promotes a thick boundary layer on the upper part of the blade. This boundary layer transition process can also be observed on the pressure coefficient distribution around the front rotor at 10,50 and $90 \%$ of the blade height based on LES shown in Fig. 11. At 50 and $90 \%$ of the blade height for the CB and SL operating points, a region of constant pressure coefficient on the SS close to the leading edge is observed characterizing the separation bubble. The boundary layer reattaches and become turbulent downstream of the separation bubble.

Compared to straight rotors, the sweeping of R1 and R2 reduces the normal Mach number and the shock losses for flight Mach number above 0.6 similarly to swept wing of commercial aircraft. This induces the development of a leading edge vortex similarly to the one observed on delta wings (see Fig. 9 bottom center). Fig. 12 shows an iso $\mathrm{Q}$-criterion at $\mathrm{Q}=10^{6}$ colored by the streamwise vorticity of the flow around the front rotor SS and rear rotor for the $\mathrm{CB}$ operating point. Under high loading at CB and SL, this vortex destabilizes the SS boundary layer characterized by a localized 


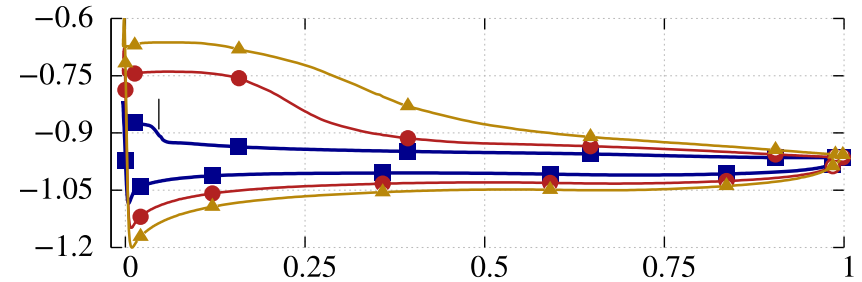

(a)

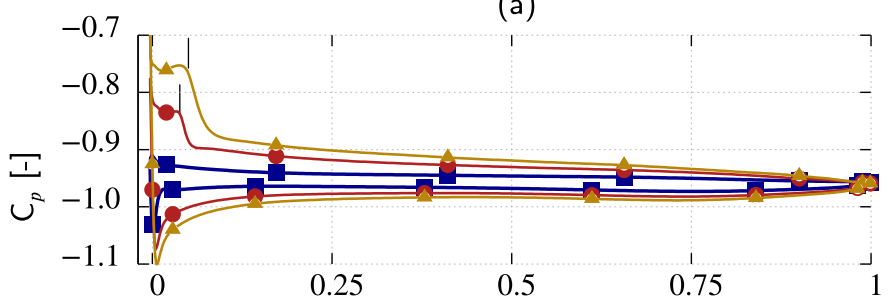

(b)

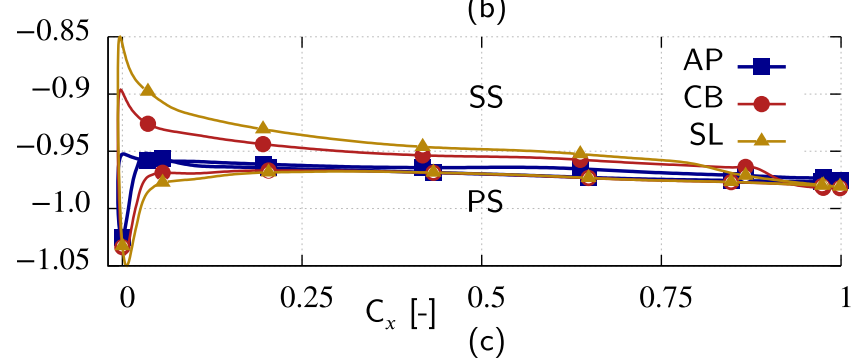

Fig. 11. Pressure coefficient distribution around the R1 blade at $90 \%$ (a), 50\% (b) and $10 \%$ (c) of the blade height for the different operating points based on the LES including transition location (vertical line).

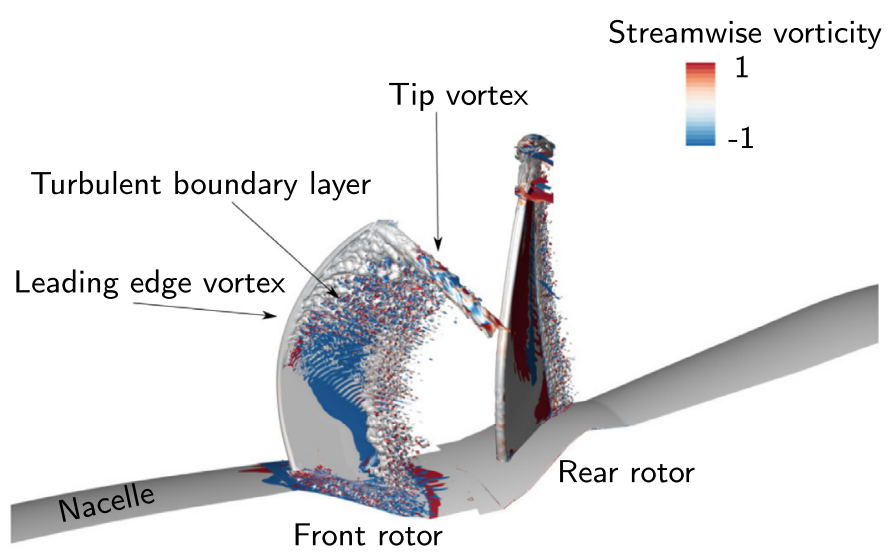

Fig. 12. Iso $Q$-criterion at $Q=10^{6}$ colored by the streamwise vorticity of the flow around the front rotor SS and rear rotor for the CB operating point.

separation bubble close to the leading edge and inducing the transition to turbulence from mid span to the tip. In the experiments, the boundary layer state on the R1 SS for the CB has been measured based on oil-painting visualizations and is shown in Fig. 13. Dark regions correspond to the regions where the oil-painting has been removed and may be associated with a turbulent boundary layer since the friction at the wall is higher compared to a laminar one. On the contrary, light areas correspond to regions where the oil-painting is maintained and may be associated with a laminar boundary layer. On the R1 SS, the boundary layer is mainly laminar until mid span in a tooth-shape pattern. On the upper part of the blade, the boundary layer is fully turbulent from the blade leading edge.

Despite the larger size of the turbulent zone in the experiments, the LES shows a good agreement for the near-wall flow topology around the $\mathrm{R} 1$ at $\mathrm{CB}$. This observation shows the better approxi-

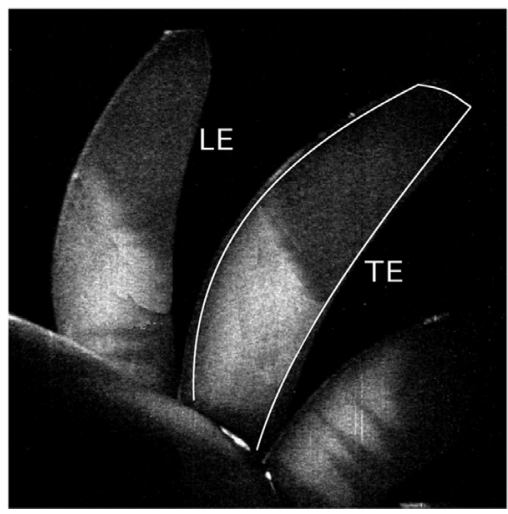

Fig. 13. Experimental oil painting visualization around the R1 SS at CB operating point.
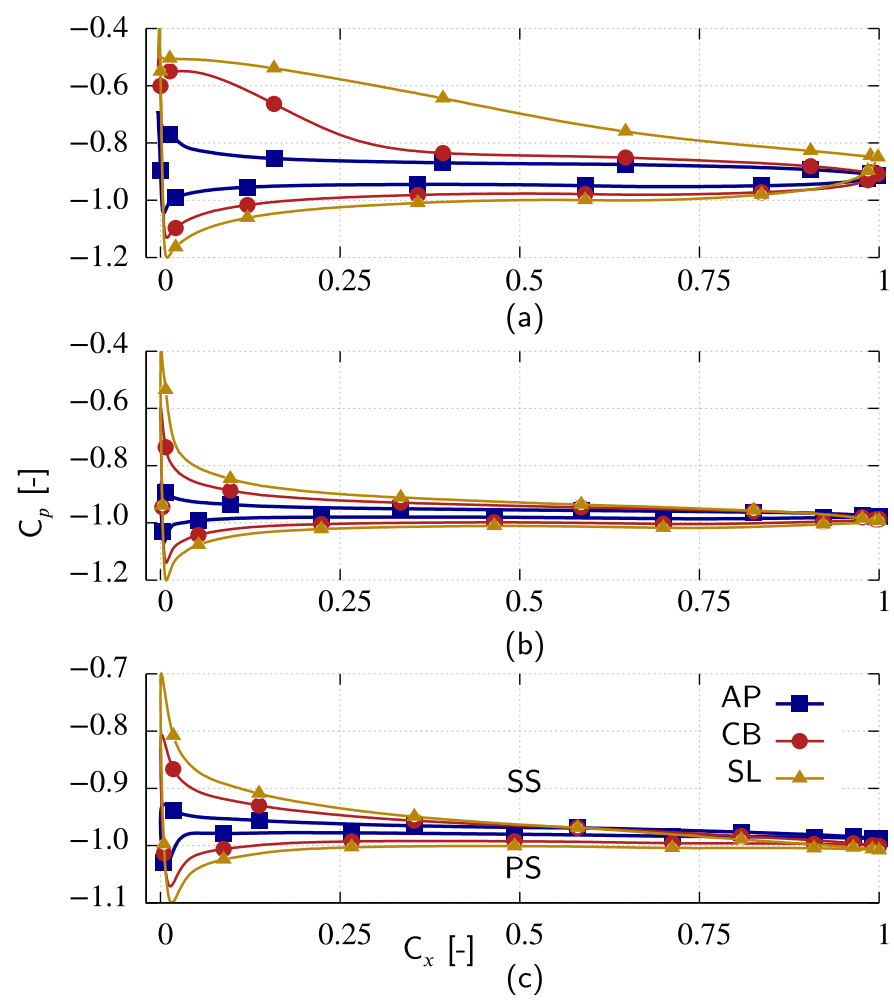

Fig. 14. Pressure coefficient distribution around the R2 blade at $90 \%$ (a), 50\% (b) and $10 \%$ (c) of the blade height for the different operating points based on the URANS.

mation of the actual flow-field by the LES compared to the URANS in the near-wall region since the transition to turbulence from mid span to the tip of the R1 SS is predicted by the LES approach compared to the URANS where the boundary layer is fully turbulent.

\section{2. $R 2$ flow topology}

The flow field topology on the PS of R2 for the URANS and LES is similar to the R1 characterized by a fully attached boundary layer at all operating points and a thicker boundary layer for the URANS approach due to a turbulent boundary layer compared to a laminar one for the LES (the wake from R1 does not induce any transition process over the PS). Fig. 14 shows the pressure coefficient distribution around the rear rotor at 10,50 and $90 \%$ at $\mathrm{AP}, \mathrm{CB}$ and SL in the URANS. In addition, the boundary layer thickness and shape factor are shown in Figs. 15 and 16 (line 1). On the 


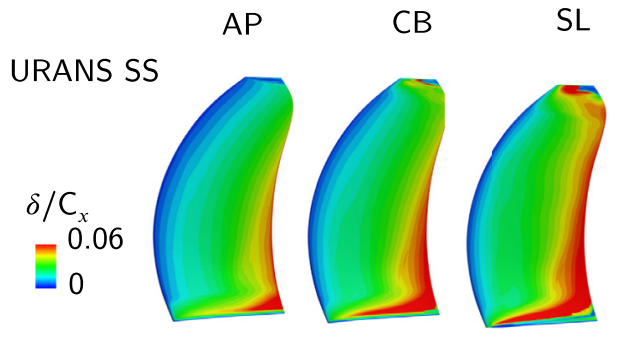

LES SS

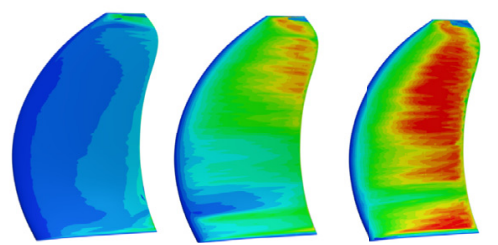

Fig. 15. Boundary layer thickness $\delta$ around the R2 SS for the URANS and LES.

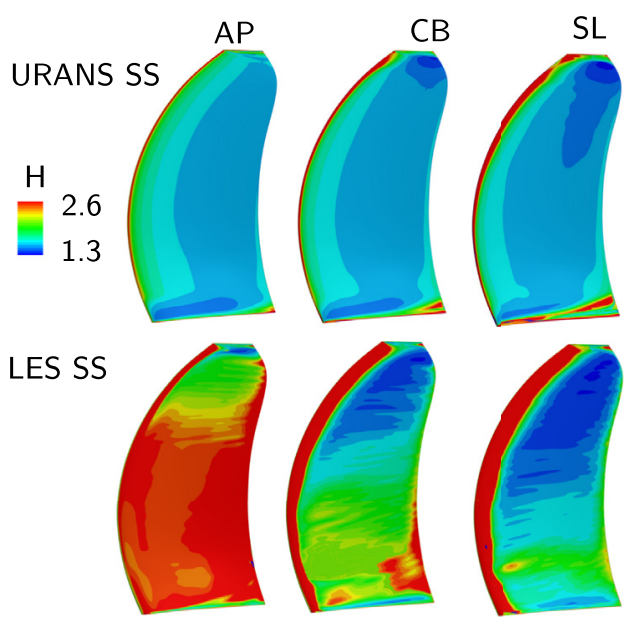

Fig. 16. Boundary layer shape factor $\mathrm{H}$ around the R2 SS for the URANS and LES,

blade SS, similarly to the R1, the boundary layer is fully turbulent and attached for the URANS approach.

In LES, the pressure distribution around the rear rotor is shown in Fig. 17 and the boundary layer thickness and shape factor around the rear rotor SS are shown in Figs. 15 and 16 line 2. For the rear rotor SS, the boundary layer becomes turbulent over the quarter upper part of the blade at the AP operating point with a region of constant pressure at $90 \%$ and a shape factor close to 1.3 . For the $\mathrm{CB}$ and SL operating points, the SS boundary layer is turbulent over the full surface and can be associated with the effect of both the leading edge vortex and turbulent wake from the R1 based on the pressure distribution and values of the shape factor.

For the R2, the pressure coefficient around the blade has the same behavior compared to the R1 with a sharp increase/decrease in the pressure coefficient around the leading edge before to reach marginal variations at mid-chord (see Fig. 14). Similarly to the front rotor, this pressure coefficient distribution decrease the losses associated with the reacceleration of the flow downstream of the shock close to the leading edge for the full scale geometry at cruise.
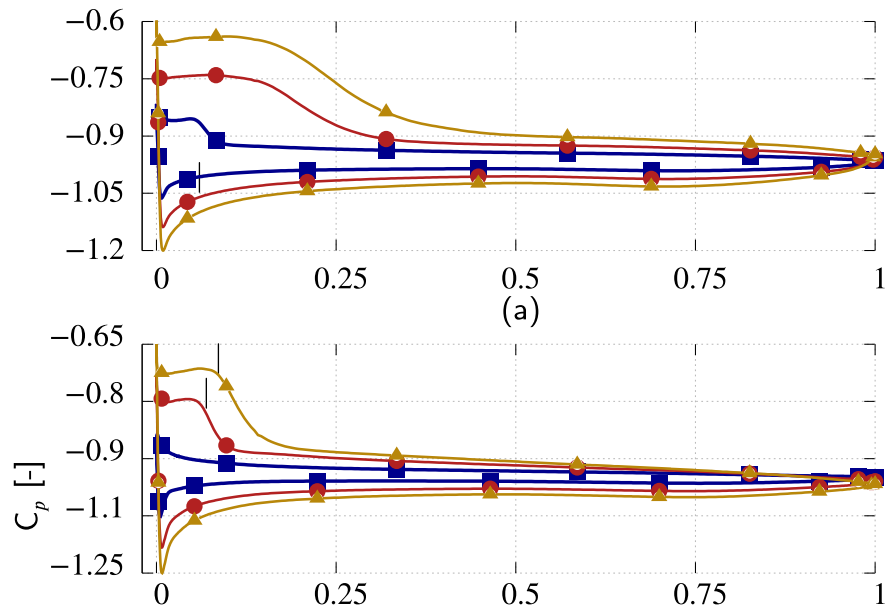

(b)

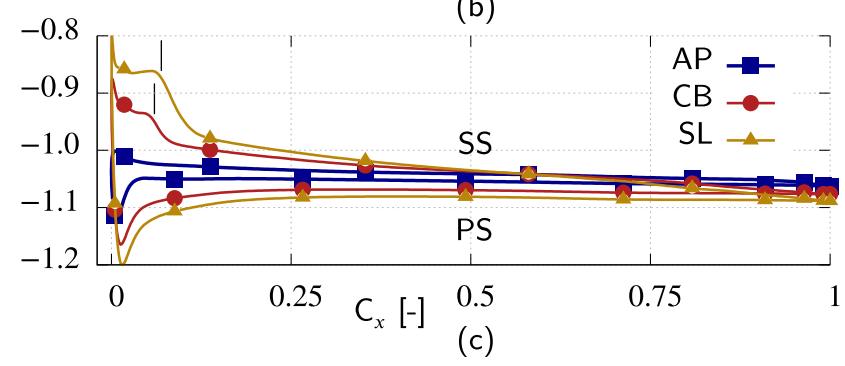

Fig. 17. Pressure coefficient distribution around the R2 blade at $90 \%$ (a), $50 \%$ (b) and $10 \%$ (c) of the blade height for the different operating points based on the LES including transition location (vertical line).

\section{Losses based on URANS and LES with PL}

\subsection{The different sources of loss}

The entropy is used to describe the losses generated in the configuration. The mono dimensional variations of this quantity are studied in the axial direction from the inlet to the outlet of the domain. The entropy produced between two axial planes (two different axial positions) can be obtained from two different approaches. The entropy can be calculated at the surface of the two planes for example using two thermodynamic quantities (see Eq. (1)) and the difference in the flux of entropy corresponds to the entropy (losses) generated in the domain enclosed by the two planes. This approach is referred to the flux approach. Alternatively, the terms provided in Eq. (2) for URANS and Eq. (5) for LES can be calculated locally in each grid cell and integrated over the volume enclosed by the two axial planes. This method is referred to the direct method. In numerical simulation, a discrepancy generally occurs between the two approaches due to numerics and mesh refinement with a lower sensitivity of the flux approach to the numerical setup. Since the study of the losses is based on the direct method, the comparison of the two approaches is first led. Fig. 18 shows the evolution of entropy along the simulation domain for the flux and direct approaches in the URANS and for the different operating points. The two approaches show a good matching with a discrepancy of around 5\% at the end of the domain. This observation gives more confidence in the use of the direct method because the trend and the magnitude agree well with the flux approach. This same comparison between the flux and direct approaches for different grid refinement levels is provided in App. Appendix A. Two types of plots are used to follow the evolution of entropy along the simulation domain based on the direct method: the volume integral between the inlet and a position $\mathrm{x}$ provides the accumulated entropy $\left(\mathrm{s}_{\mathrm{acc}}\right)$ (see Fig. 19 top left); the integration over 


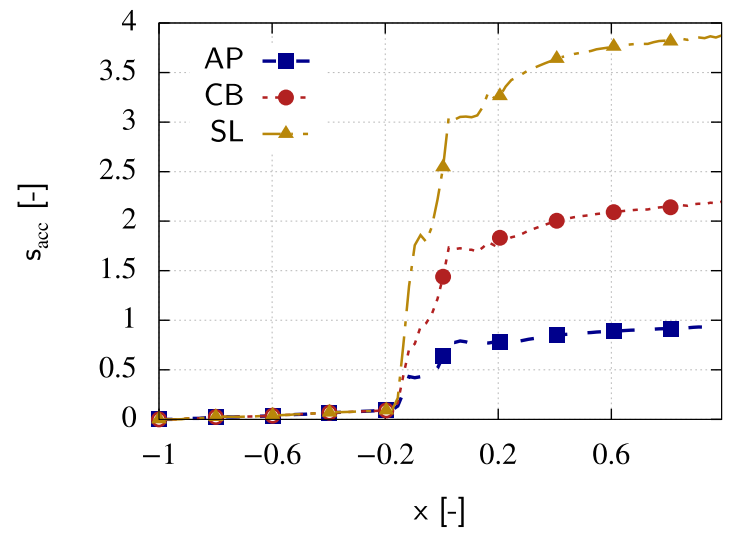

(a)

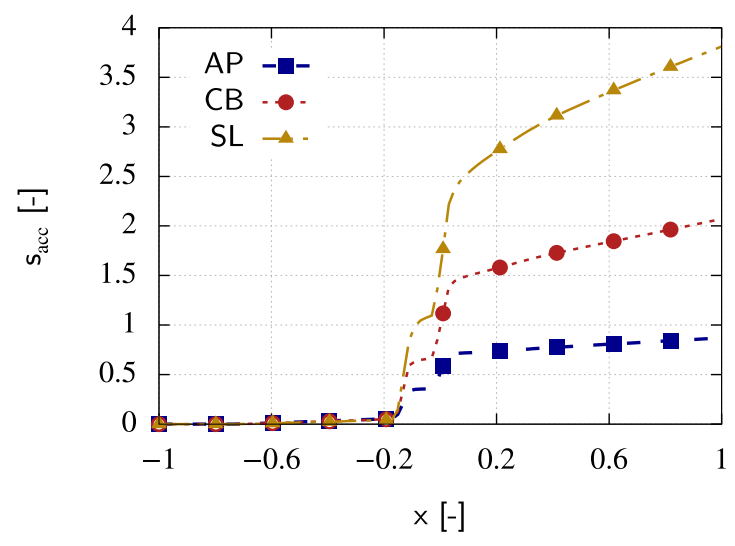

(b)

Fig. 18. Accumulated entropy in the simulation domain for the different operating points based on the flux (a) and direct method (b).

a small axial control volume of axial length $\mathrm{dx}$ around the position $x$ provides the entropy production $\left(s_{\text {prod }}\right)$ and is used to highlight the areas of strong entropy production, i.e. strong losses (see Fig. 19 top right).

The total, laminar and turbulent contribution to the accumulated entropy for the URANS approach and AP operating point are shown in Fig. 20. The entropy starts to increase at the front of the nacelle between $x / C_{x}=0.6$ to 0.2 . The entropy strongly increases along the extent of the $\mathrm{R} 1$ and $\mathrm{R} 2$ between $\mathrm{x} / \mathrm{C}_{x}=-0.2$ and 0.05 . Downstream of the two rotor rows, the entropy keeps increasing with a lower slope compared to the rotors region. The laminar and turbulent contributions follow the same trend along the simulation domain compared to the total contribution. The turbulent contribution is dominant corresponding to $66 \%$ of the total losses and $34 \%$ for the laminar one. This ratio between laminar and turbulent contributions is relatively constant for the different operating points.

Based on the boundary layer edge detection method introduced in previous Section 5, the boundary layer thickness can be obtained for the different wetted surfaces of the domain (hub, R1 and $\mathrm{R} 2$ ) and the corresponding volumes $\mathcal{V}_{\mathrm{hub}}, \mathcal{V}_{\mathrm{R} 1}, \mathcal{V}_{\mathrm{R} 2}$. The full simulation domain less the boundary layer contributions provides the remaining domain with an associated volume $\mathcal{V}_{\text {rem. }}$ term. The direct method is applied to these restricted domains to obtain the contributions of the different boundary layers and the remaining domain in a similar manner to previous studies of the losses in gas turbines [12,13,19,27] (see Fig. 19 bottom). The different figures related to the contributions of the boundary layers and the remaining domain are shown in conjunction with the total con-

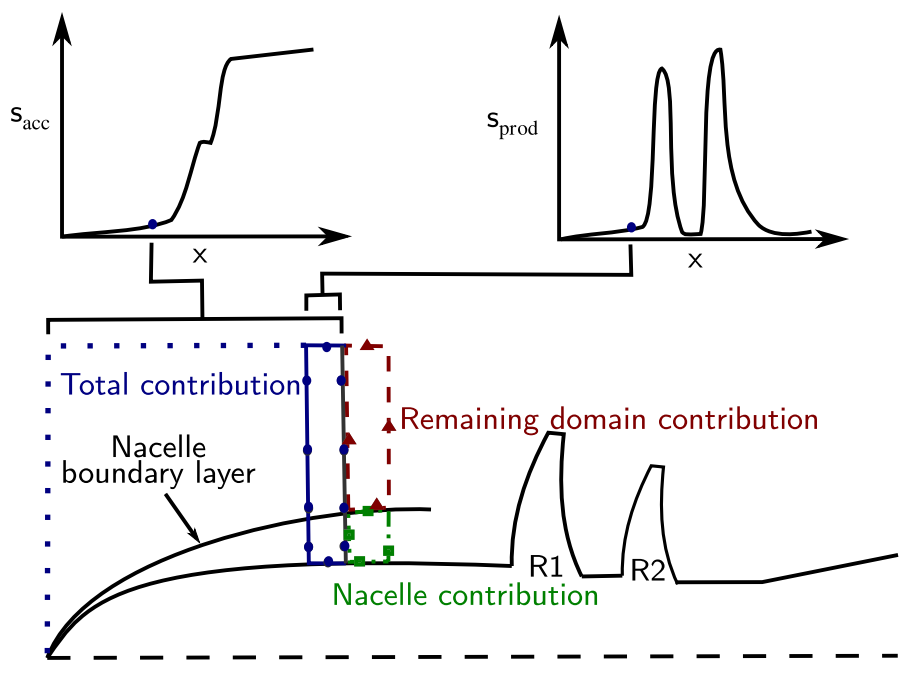

Fig. 19. Simulation domain discretized in axial subvolumes (dark blue). This subvolume can be split into two subvolumes: the nacelle boundary layer (green) and its complement corresponding to the whole subvolume less the subvolume associated with the nacelle boundary layer (red). (For interpretation of the references to colour in this figure legend, the reader is referred to the web version of this article.)

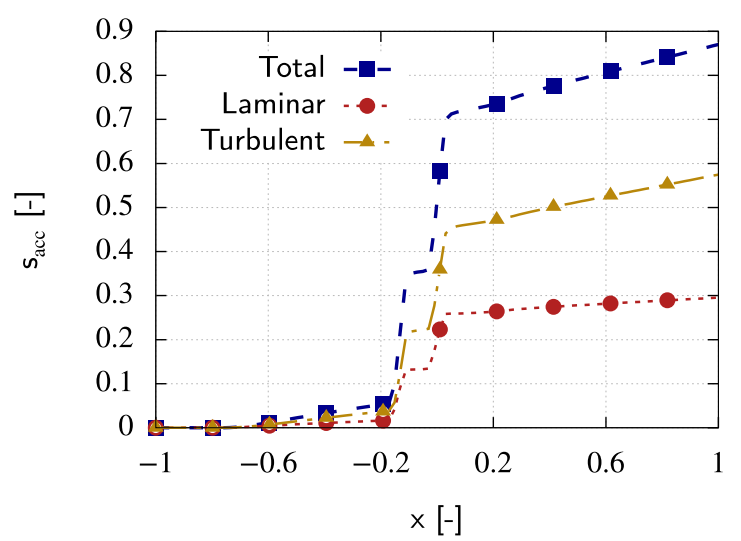

Fig. 20. Accumulated entropy in the simulation domain for the AP operating points based on the different contributions.

tribution of the domain at the same abscissa to give the reader the magnitude of the contribution compared to the total one. This analysis led for the AP operating point and the URANS approach is shown in Fig. 21. The entropy accumulated from the front of the nacelle $\left(x / C_{x}=0.75\right)$ up to the first rotor row $\left(x / C_{x}=-0.2\right)$ is only due to the boundary layer developing over the hub of the configuration. The hub boundary layer contribution increases linearly along the simulation domain. The region of sharp increase in entropy corresponds to the two rotor rows and are associated with the boundary layers developing on the blade SS and PS. When these different boundary layer contributions are subtracted from the total contribution, the losses associated with secondary flows and wakes can be obtained. This contribution starts to increase at the rear of the R1 and increases strongly downstream of the R2 before to become constant downstream. The different contributions can be integrated over the domain to obtain the influence on the total amount of losses generated. Table 2 gathers the different contributions for the different operating points based on the URANS approach.

For the AP operating point, the hub boundary layer contribution represents around $25.8 \%$ of the total losses generated. The R1 boundary layer contribution is around 37.3\%. The R2 generates more losses compared to the $\mathrm{R} 1$ with around $41.1 \%$ of losses. When 


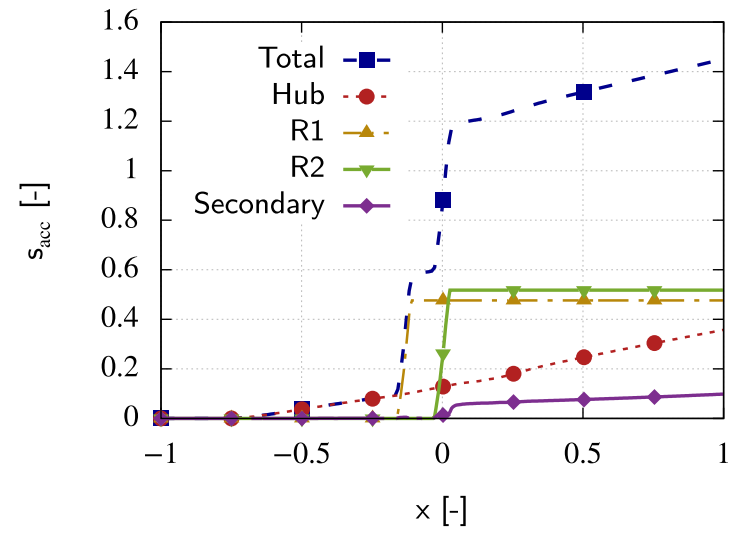

Fig. 21. Accumulated entropy in the simulation domain for the AP operating points based on the different contributions (URANS).

Table 2

Distribution of losses for the different operating points based on the URANS approach.

\begin{tabular}{llll}
\hline Contribution & AP & CB & SL \\
\hline Total & 1.597 & 4.142 & 6.699 \\
Hub & $0.412(25.8 \%)$ & $0.655(15.8 \%)$ & $0.910(13.6 \%)$ \\
Rotor 1 & $0.597(37.3 \%)$ & $1.416(34.2 \%)$ & $2.175(32.4 \%)$ \\
Rotor 1 SS & $0.350(21.9 \%)$ & $1.038(25.0 \%)$ & $1.710(25.5 \%)$ \\
Rotor 1 PS & $0.247(15.4 \%)$ & $0.378(9.2 \%)$ & $0.465(6.9 \%)$ \\
Rotor 2 & $0.657(41.1 \%)$ & $1.576(38 \%)$ & $2.696(40.2 \%)$ \\
Rotor 2 SS & $0.385(24.1 \%)$ & $1.033(24.9 \%)$ & $1.932(28.8 \%)$ \\
Rotor 2 PS & $0.272(17.0 \%)$ & $0.543(13.1 \%)$ & $0.764(11.4 \%)$ \\
Secondary flow & $0.104(7.3 \%)$ & $0.495(12.0 \%)$ & $0.875(13.0 \%)$ \\
\hline
\end{tabular}

Table 3

Distribution of losses for the different operating points based on the LES approach.

\begin{tabular}{llll}
\hline Contribution & AP & CB & SL \\
\hline Total & 1.052 & 4.020 & 6.102 \\
Hub & $0.205(23.9 \%)$ & $0.474(11.8 \%)$ & $0.561(9.2 \%)$ \\
Rotor 1 & $0.371(32.2 \%)$ & $1.519(37.8 \%)$ & $2.330(38.2 \%)$ \\
Rotor 1 SS & $(20.1 \%)$ & $1.038(28.6 \%)$ & $1.806(29.6 \%)$ \\
Rotor 1 PS & $0.247(11.1 \%)$ & $0.378(9.2 \%)$ & $0.525(8.6 \%)$ \\
Rotor 2 & $0.385(36.6 \%)$ & $1.632(40.6 \%)$ & $2.532(41.5 \%)$ \\
Rotor 2 SS & $0.243(23.1 \%)$ & $1.033(28.5 \%)$ & $1.837(30.1 \%)$ \\
Rotor 2 PS & $0.142(13.5 \%)$ & $0.543(12.1 \%)$ & $0.696(11.4 \%)$ \\
Secondary flow & $0.089(7.3 \%)$ & $0.393(9.8 \%)$ & $0.677(11.1 \%)$ \\
\hline
\end{tabular}

splitting between the SS and PS boundary layer contributions, the SS represents around $2 / 3$ of the total rotor contribution and $1 / 3$ for the PS. The losses related to secondary flows and wakes correspond to $7.3 \%$ of the total losses. When the rotational velocity is increased, the hub contribution decreases at respectively $15.8 \%$ and $13.6 \%$ for the $\mathrm{CB}$ and SL operating points. The R1 boundary layer contribution also decreases, respectively $34.2 \%$ and $32.4 \%$ for CB and SL operating points. The main decrease of losses occurs over the PS, $9.2 \%$ and $6.9 \%$ for the CB and SL operating points while the SS contribution is relatively constant at $25 \%$ and $25.5 \%$ for the CB and SL operating points. The losses associated with the R2 boundary layer are relatively constant (around $40 \%$ of losses for the different operating points) with an increase of the SS contribution compensated by a decrease of the PS contribution. Also, when the rotational velocity is increased, secondary flow losses are also increased. This increase of losses can be associated with the stronger pressure difference between the PS and SS leading to a more energetic tip vortex at the tip of R1 and R2.

In the LES, the distribution of losses at AP for the different contribution is shown in Fig. 22 and the associated integrated losses are gathered in Table 3. At AP, the total amount of losses gen-

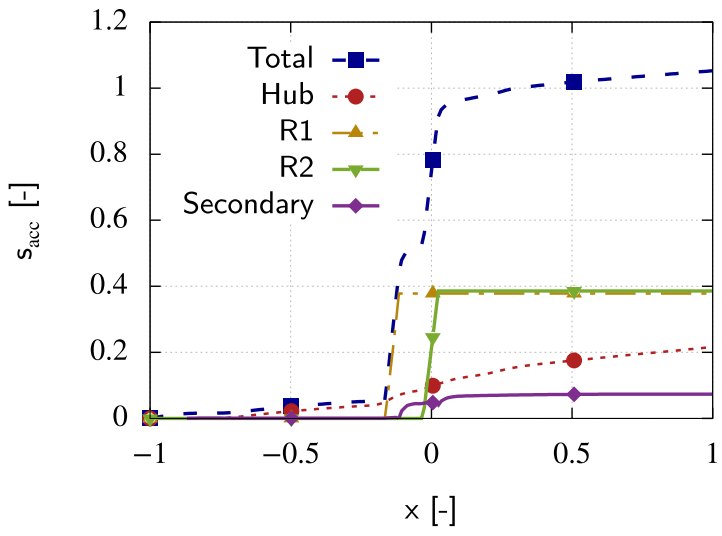

Fig. 22. Accumulated entropy in the simulation domain for the AP operating points based on the different contributions (LES).

erated is lower compared to the URANS approach (1.057 for the LES against 1.597 for the URANS). This difference can be attributed to the development of laminar boundary layers over the different wetted surfaces in the LES compared to the URANS approach with turbulent boundary layers. When the rotational velocity is increased, the total level of losses in the LES is similar to the losses of the URANS approach (4.020 for the LES against 4.142 for the URANS). This behavior can be related to the leading edge vortex causing the SS boundary layer to become turbulent on the upper part of the blade in the LES. As a consequence, an increase of the relative magnitude of the R1 SS boundary layer at $C B$ can be observed compared to the AP operating point (20.1\% for the AP against $28.6 \%$ for the $\mathrm{CB}$ ). For the R2 SS, the turbulent wake from the R1 and the leading edge vortex induce the transition of the boundary layer and promote more losses compared to the AP operating point $(23.1 \%$ for the AP operating point against $28.5 \%$ for the $\mathrm{CB}$ operating point). The total level of losses remains however marginally lower compared to the URANS. This can be attributed to the PS boundary layers of the R1 and R2 that remain laminar compared to the URANS approach with turbulent boundary layers, the PS contribution remaining relatively constant between the AP and $\mathrm{CB}$ operating points. For the SL operating point, the same conclusions observed at CB can be drawn. The R1 and R2 SS boundary layer contributions are higher compared to the AP operating point due to a turbulent boundary layer over the majority of the blades SS. More generally, the general trends observed in URANS are conserved: the relative contribution of the hub boundary layer decreases with the increase of rotating velocity while the secondary flow losses increase. The contributions of the SS boundary layers increase with the rotating velocity while the PS contributions remain constant or tend to decrease.

The production of entropy $s_{\text {prod }}$ in the boundary layer for the R1 and R2 along the blade on the SS and PS is provided based on the LES approach in Fig. 23 where the curves are normalized by their maximum value. For the R1 and R2 SS boundary layers, the generation of losses increases linearly on the front region of the blade associated with the acceleration of the flow until around $\mathrm{x} / \mathrm{C}_{x}=0.6-0.7$ where it reaches its maximum value. On the rear region of the blade, the flow decelerates and the losses decrease until the TE. The mean viscous dissipation close to the tip of the rotors is stronger compared to the regions close to the hub due to higher velocity gradients. Also, the TKE production mainly occurs from mid to the tip span where the boundary layer transition occurs at CB and SL and where the turbulent boundary layer develops downstream of the leading edge vortex. On the PS, the entropy generation increases linearly until $\mathrm{x} / \mathrm{C}_{x}=0.6$ then the losses more sharply increase until $\mathrm{x} / \mathrm{C}_{x}=0.8$ before to decrease until the 


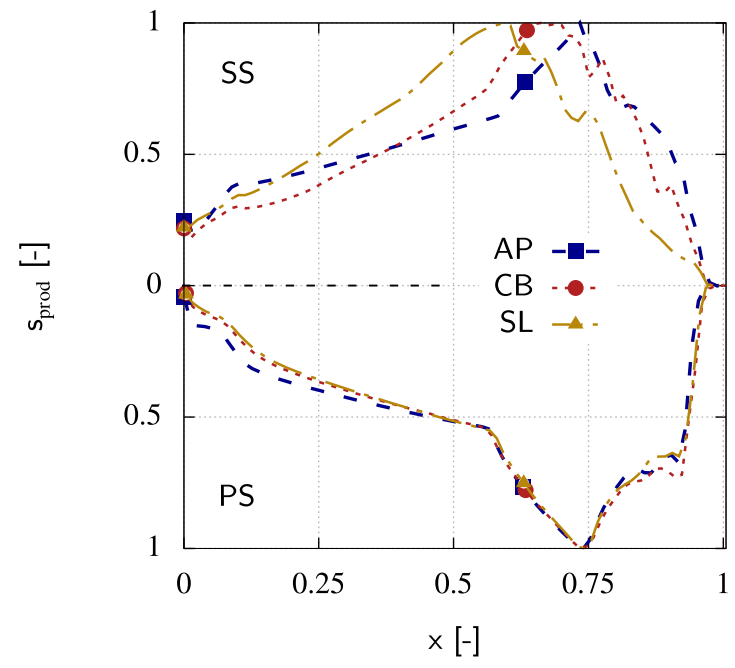

(a)

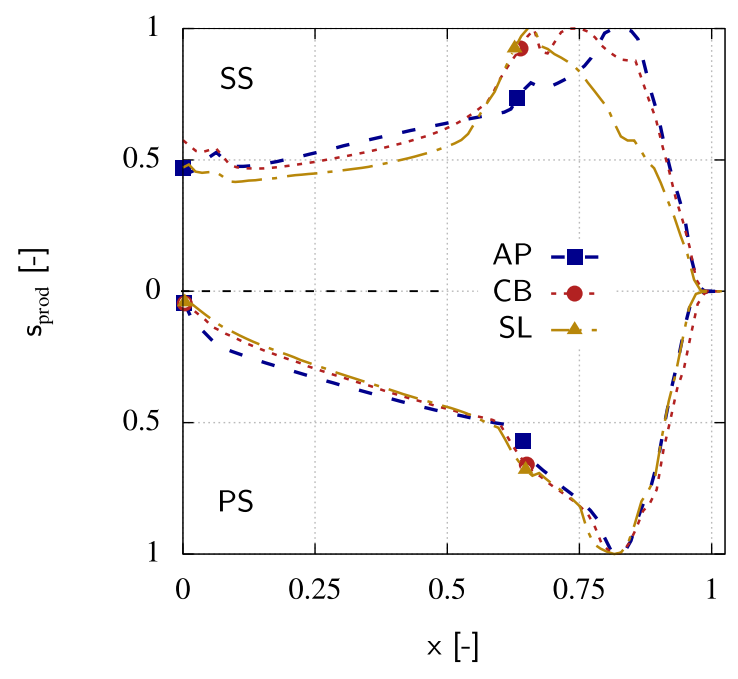

(b)

Fig. 23. Entropy produced in the boundary layer of R1 (a) and R2 (b) for the different operating points based on LES.

TE. The general shape of entropy production is relatively insensitive to the rotational speed. For the SS, the maximum of entropy production is progressively moved upstream and can be associated with the transition to the turbulent regimes for the two higher rotational speed ( $\mathrm{CB}$ and $\mathrm{SL}$ ) causing the losses to occur earlier on the blade SS.

\section{Conclusion}

The numerical simulation of a counter rotating open rotor configuration for three different operating points (approach, cutback and sideline) has been performed based on URANS and LES approaches with phase-lagged assumption and POD data storage.

The URANS approach predicts turbulent boundary layers over the front and rear rotors of the configuration for the different operating points. In LES, the front rotor is fully laminar for the approach operating point and turbulent only close to the tip for the rear rotor suction side. At cutback and sideline, the suction side boundary layer becomes turbulent from mid-span to the tip due to the leading edge vortex. The rear rotor suction side boundary layer becomes turbulent over the full span due to the effects of both the leading edge vortex and the turbulent structures from the wake of the front rotor.

The level of losses for the approach operating point is lower for the LES compared to URANS due to the laminar boundary layer over the blades compared to a turbulent state for URANS. At cutback and sideline operating points, the level of losses becomes comparable between URANS and LES due to a transition to a turbulent state of the suction side boundary layers in LES at these two operating points.

The two numerical approaches show a similar trend for the losses generated: the front and rear rotors boundary layers are strong contributors to the losses with around $30 \%$ of losses for the front and 40\% for the rear rotor. This boundary layer contribution increases with the increase of the rotational velocity as well as the secondary flows at the expense of the nacelle boundary layer contribution.

\section{Declaration of Competing Interest}

The authors declare that they have no known competing financial interests or personal relationships that could have appeared to influence the work reported in this paper.

\section{CRediT authorship contribution statement}

M. Fiore: Conceptualization, Formal analysis, Investigation, Writing - review \& editing. M. Daroukh: Validation, Formal analysis, Investigation. M. Montagnac: Methodology, Software, Data curation, Resources, Supervision.

\section{Acknowledgments}

The authors are thankful to Airbus Operation SAS for technical support and experimental data provided, DLR for PIV experimental measurements, the European Commission for having funded this research project within the project SCONE (Grant agreement ID: 755543), to ONERA for licensing Cerfacs to use code elsA (ONERA-Airbus-Safran property). Numerical post-processing has been performed using the free python-based Library Antares. Part of this work was performed using HPC resources from GENCI[CCRT-CINES-IDRIS] (Grant 2019-[A0042A06074]).

\section{Appendix A. Mesh dependency}

The assessment of the grid convergence is made by comparing the evolution of entropy along the simulation domain for three levels of grid refinement and the two methods used to calculate entropy (two independent thermodynamic quantities and direct method) for the full CROR configuration R12PL at CB. This quantity is used due to the large sensitivity to the mesh refinement [48] and its use to evaluate the losses generated in the configuration. In the structured approach, the mesh has been designed with $4 \mathrm{~N}+1$ grid points in any mesh block where $\mathrm{N} \in \mathbb{N}^{*}$. This makes possible in the simulation to consider cells in each direction that cover twice or four cells of the most refined mesh. This corresponds to a refined mesh with $350 \times 10^{6}$ cells (M1), intermediate $1 / 2$ mesh with $44 \times 10^{6}$ cells (M2) and $1 / 4$ coarse mesh with $5.5 \times 10^{6}$ cells (M3). The entropy production for the three grid refinement levels are show in Fig. 24a for the entropy calculated with thermodynamic quantities and Fig. 24b for the entropy calculated using the direct method. The two approaches show same trends along the simulation but a mismatch in amplitude for the two coarser meshes M2 and M3. For the most refined mesh M1 used during the study, the two approaches used to compute entropy are in good agreement in terms of trend along the simulation domain and level at the end of the domain with a mismatch 


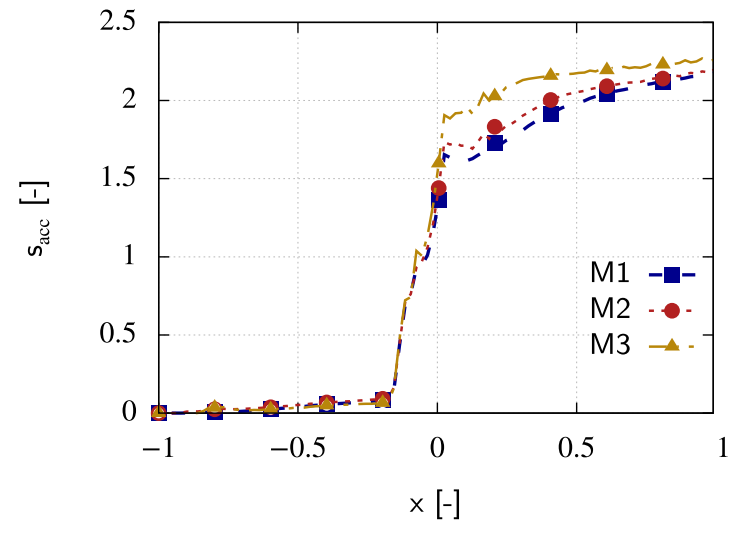

(a)

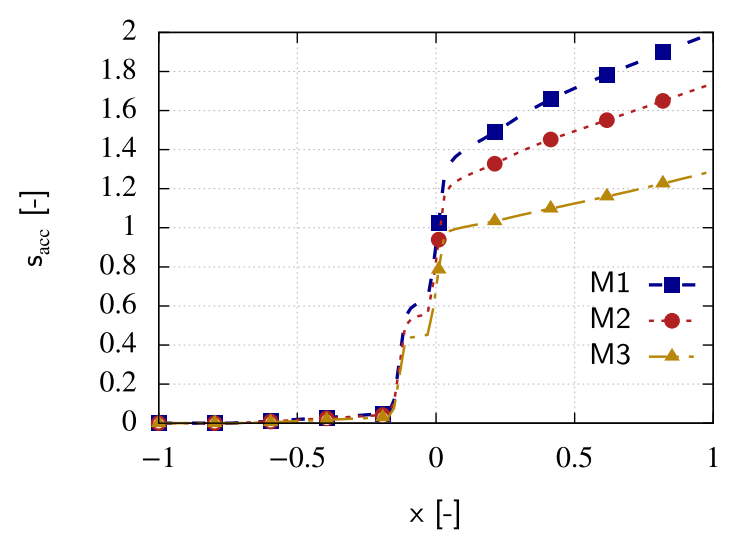

(b)

Fig. 24. Accumlated Entropy in the simulation domain based on flux (a) and direct method (b) for the CB operating point at three different mesh refinements.

of around $5 \%$. This comparison indicates that the mesh M1 is suitable for the study and evaluate the losses generated in the configuration.

\section{References}

[1] Adrian RJ. Twenty years of particle image velocimetry. Exp Fluids 2005;39(6):159-69. doi:10.1007/s00348-005-0991-7.

[2] Berkooz G. The proper orthogonal decomposition in the analysis of turbulent flows. Annu Rev Fluid Mech 2002;25:539-75. doi:10.1146/annurev.fluid.25.1. 539.

[3] Cambier L, Heib S, Plot S. The onera elsa CFD software: input from research and feedback from industry. Mech Ind 2013;14(3):159-74. doi:10.1051/meca/ 2013056. http://www.mechanics-industry.org/10.1051/meca/2013056

[4] Carazo A, Roger M, Omais M. Analytical prediction of wake-interaction noise in counter-rotating open rotors. In: Proceedings of the 17th AIAA/CEAS aeroacoustics conference (32nd AIAA aeroacoustics conference). Portland, Oregon: AIAA; 2012. https://doi.org/10.2514/6.2011-2758.

[5] Cliquet J, Houdeville R, Arnal D. Application of laminar-turbulent transition criteria in Navier-Stokes computations. AIAA J 2008;46(5):1182-90. doi:10.2514/ 1.30215 .

[6] Colin Y, Blanc F, Caruelle B, Barrois F, Djordjevic N. Computational strategy for predicting CROR noise at low-speed Part II: investigation of the noise sources computation with the chorochronic method. In: Proceedings of the 18th AIAA/CEAS aeroacoustics conference (33rd AIAA aeroacoustics conference). Colorado Springs: AIAA; 2012. https://doi.org/10.2514/6.2012-2222.

[7] Colin Y, Carazo A, Caruelle B, Node-Langlois T, Parry A. Computational strategy for predicting CROR noise at low-speed Part I: review of the numerical methods. In: Proceedings of the 18th AIAA/CEAS aeroacoustics conference (33rd AIAA aeroacoustics conference). Colorado Springs: AIAA; 2012. https://doi.org/ 10.2514/6.2012-2221.

[8] Colin Y, Caruelle B, Parry A. Computational strategy for predicting CROR noise at low-speed Part III: investigation of noise radiation with the Ffowcs-Williams Hawkings analogy. In: Proceedings of the 18th AIAA/CEAS aeroacoustics conference (33rd AIAA aeroacoustics conference). Colorado Springs: AIAA; 2012. https://doi.org/10.2514/6.2012-2223.
[9] Cousteix J. Three-dimensional and unsteady boundary-Layer computations. Annu Rev Fluid Mech 1986;18(2):173-96. doi:10.1146/annurev.fluid.18.1.173.

[10] Delattre G, Falissard F. Influence of torque ratio on counter-rotating open-rotor interaction noise. AIAA J 2015;53(9):2726-38. doi:10.2514/1.J053797.

[11] Delattre G, Falissard F, Vion L, Jacquin L. Open rotor interaction noise reduction through front rotor wake modification. Int J Aeroacoustics 2016;15(2):207-27. doi: $10.1177 / 1475472 X 16643461$.

[12] Denton JD. Loss mechanisms in turbomachines. J Turbomach 1993;115(4):621. doi:10.1115/1.2929299.

[13] Denton JD, Pullan G. A numerical investigation into the sources of endwall loss in axial flow turbines. In: Volume 8: Turbomachinery, Parts A, B, and C; 2012. p. 1417. ISBN 978-0-7918-4474-8. doi:10.1115/GT2012-69173.

[14] Erdos J. Alzner E. Computation of unsteady transonic flows through rotating and stationary cascades. 1: method of analysis. Technical Reports. National Aeronautics and Space Administration; 1977.

[15] Giauque A, Ortun B, Rodriguez B, Caruelle B. Numerical error analysis with application to transonic propeller aeroacoustics. Comput Fluids 2012;69(3):2034. doi:10.1016/j.compfluid.2012.07.022.

[16] Gourdain N. Prediction of the unsteady turbulent flow in an axial compressor stage. Part 1: comparison of unsteady RANS and LES with experiments. Comput Fluids 2015. doi:10.1016/j.compfluid.2014.09.052.

[17] Gourdain N. Prediction of the unsteady turbulent flow in an axial compressor stage. Part 2: analysis of unsteady RANS and LES data. Comput Fluids 2015. doi:10.1016/j.compfluid.2014.09.044.

[18] Gourdain N, Sicot F, Duchaine F, Gicquel L. Large eddy simulation of flows in industrial compressors: a path from 2015 to 2035. Philos Trans R Soc A 2014;372(2022):20130323. doi:10.1098/rsta.2013.0323.

[19] Hammer F, Sandham N, Sandberg R. The influence of different wake profiles on losses in a low pressure turbine cascade. Int J Turbomach Propuls Power 2018. doi:10.3390/ijtpp3020010.

[20] He L. Method of simulating unsteady turbomachinery flows with multiple perturbations. AIAA J 1992;30(11):2730-5. doi:10.2514/3.11291.

[21] He L. Fourier methods for turbomachinery applications. Prog Aerosp Sci 2010;46(8):329-41. doi:10.1016/j.paerosci.2010.04.001.

[22] Hendricks E, Tong M. Performance and weight estimates for an advanced open rotor engine. In: Proceedings of the 48th AIAA/ASME/SAE/ASEE Joint Propulsion Conference \& Exhibit. Atlanta, Georgia: AIAA; 2012. https://doi.org/10. 2514/6.2012-3911.

[23] Jameson A, Schmidt W, Turkel E. Numerical solutions of the Euler equations by finite volume methods using Runge-Kutta time-stepping schemes. AIAA Paper 1981;6(2):1259. doi:10.2514/6.1981-1259.

[24] Kim WY, Senguttuvan S, Kim SM. Effect of rotor spacing and duct diffusion angle on the aerodynamic performances of a counter-rotating Ducted fan in hover mode. Processes 2020;8(11):112-26. doi:10.3390/pr8111338.

[25] Lengani D, Simoni D, Ubaldi M, Zunino P, Bertini F. A POD-Based procedure for the split of unsteady losses of an LPT cascade. Int J Turbomach Propuls Power 2017;2(4):17. doi:10.3390/ijtpp2040017.

[26] Lengani D, Simoni D, Ubaldi M, Zunino P, Bertini F, Michelassi V. Accurate estimation of profile losses and analysis of loss generation mechanisms in a turbine cascade. J Turbomach 2017;139(12):121-32. doi:10.1115/1.4037858.

[27] Lengani D, Simoni D, Pichler R, Sandberg RD, Michelassi V, Bertini F. Identification and quantification of losses in a LPT cascade by POD applied to LES data. Int J Heat Fluid Flow 2018;70:28-40. doi:10.1016/j.ijheatfluidflow.2018.01.011.

[28] Lepot I, Leborgne M, Schnell R, Yin J, Delattre G, Falissard F, et al. Aeromechanical optimization of a contra-rotating open rotor and assessment of its aerodynamic and acoustic characteristics. In: Proceedings of the Institution of Mechanical Engineers, Part A: Journal of Power and Energy; 2011. https://doi.org/10.1177/0957650911413695.

[29] Marmignon C, Couaillier V, Courbet B. Solution strategies for integration of semi-discretized flow equations in elsa and CEDRE. AerospaceLab J $2011 ; 2(1): 1-11$

[30] Michelassi V, Wissink JG. Turbulent kinetic energy production in the vane of a low-pressure linear turbine cascade with incoming wakes. Int J Rotat Mach 2015;2015(2). doi:10.1155/2015/650783.

[31] Moore J, Moore JG. Entropy production rates from viscous flow calculations: Part I - a turbulent boundary layer flow. Volume 1: Turbomachinery. Phoenix, Arizona: ASME; 1983. ISBN 978-0-7918-7951-1. doi:101115/83-GT-70. V001T01A032

[32] Mouret G, Gourdain N, Castillon L. Adaptation of phase-lagged boundary conditions to large eddy simulation in turbomachinery configurations. J Turbomach 2015;138(4):041003. doi:10.1115/1.4032044.

[33] Negulescu CA. Airbus AI-PX7 CROR design features and aerodynamics. SAE Int J Aerosp 2013;6(2):626-42. doi:10.4271/2013-01-2245.

[34] Nicoud F, Ducros F. Subgrid-scale stress modelling based on the square of the velocity gradient tensor. Flow Turbul Combust 1999;62(3):183-200. doi:10. 1023/A:1009995426001.

[35] Nishikawa H, Rad M, Roe P. A third-order fluctuation splitting scheme that preserves potential flow. In: Proceedings of the 15th AIAA computational fluid dynamics conference; 2013. https://doi.org/10.2514/6.2001-2595.

[36] Novara M, Geisler R, Schröder A. Multi-stereo PIV measurement of propeller wake flow in industrial facility. In: Proceedings of the 31st AIAA aerodynamic measurement technology and ground testing conference; 2015. ISBN 9781624103643. https://doi.org/10.2514/6.2015-2867.

[37] Pichler R, Zhao Y, Sandberg RD, Michelassi V, Pacciani R, Marconcini M, et al. LES and RANS analysis of the end-wall flow in a linear LPT cascade with variable inlet conditions, Part I: Flow and secondary vorticity fields. In: Proceed- 
ings of the ASME turbo expo 2018: turbomachinery technical conference and exposition. Oslo, Norway: ASME; 2018. https://doi.org/10.1115/GT2018-76450.

[38] Piomelli U. Wall-layer models for large-eddy simulations. Prog Aerosp Sci 2008;44(6):437-46. doi:10.1016/j.paerosci.2008.06.001. 1505.05786

[39] Ricouard J, Julliard E, Omais M, Regnier V, Parry A, Baralon S. Installation effects on contra-rotating open rotor noise. In: Proceedings of the 16th AIAA/CEAS Aeroacoustics Conference. Atlanta, Georgia: AIAA; 2010. ISBN 9781-60086-955-6. https://doi.org/10.2514/6.2010-3795.

[40] Roy B, Ravibabu K, Rao P, Basu S, Raju A, Murthy PN. Flow studies in Ducted twin-rotor contra-rotating axial flow fans. In: Proceedings of the ASME 1992 International Gas Turbine and Aeroengine Congress and Exposition, GT 1992; 1992. ISBN 9780791878934. https://doi.org/10.1115/92-GT-390.

[41] Sagaut P. Large Eddy simulation for incompressible flows: an introduction. Springer Science \& Business Media; 2006. doi:101007/b137536.

[42] Schlichting H, Gersten K. Boundary layer theory, 9; 2001. ISBN 0070553343. doi:101016/S0997-7546(00)01101-8. http://linkinghub.elsevier.com/retrieve/ pii/S0997754600011018
[43] Thwaites B. Incompressible aerodynamics: an account of the theory and observation of the steady flow of incompressible fluid past aerofoils, wings, and other bodies. University of Washington; 1960.

[44] Tucker PG. Computation of unsteady turbomachinery flows: part 2-LES and hybrids. Prog Aerosp Sci 2011;47(7):546-69. doi:10.1016/j.paerosci.2011.07.002.

[45] Van Zante DE. Progress in open rotor research: A U.S. perspective. In: Proceedings of the ASME Turbo Expo. Montreal, Quebec, Canada: ASME; 2015. p. 12031. ISBN 9780791856628. doi:10.1115/GT2015-42203.

[46] Wheeler APS, Sandberg R, Sandham ND, Pichler R, Michelassi V, Laskowski G. Direct numerical simulations of a high-Pressure turbine vane. J Turbomach 2016;138(7):071003. doi:10.1115/1.4032435.

[47] Wilcox DC. Formulation of the k- $\omega$ turbulence model revisited. AIAA J 2008. doi:10.2514/1.36541.

[48] Zlatinov MB, Sooi Tan C, Montgomery M, Islam T, Harris M. Turbine hub and shroud sealing flow loss mechanisms. J Turbomach 2012;134(6):061027. doi:10. $1115 / 1.4006294$. 